\title{
Studies on the chironomid midges (Diptera, Chironomidae) of the Lake Toba area, Sumatra, Indonesia
}

\author{
Mihoko KIKUahi* and Manabu SASA* \\ Toyama Kokusai Daigaku (Toyama University of International Studies), \\ Oyama-cho, Toyama 930-12, Japan
}

(Received: April 23, 1990)

Key words: Chironomidae, Diptera, Indonesia, new species, Sumatra, taxonomy.

\begin{abstract}
The senior author visited Lake Toba, Sumatra, Indonesia, three times during the period from January 1987 to January 1989, for the collection of chironomid midges breeding in and around this lake. The adult midges resting or swarming around the lake were collected during the daytime with insect net or sucking tubes. The midges attracted at night to a battery-operated 6 -watt white light were also collected with sucking tubes or insect net. A total of 101 adult males among the collections were mounted on slides with gum-chloral medium and identified. They were classified into 31 species, or 26 species of Chironominae (19 species of Chironomini and 7 species of Tanytarsini) and 5 species of Orthocladiinae ( 3 species of Orthocladiini and 2 species of Metriocnemini). Among these species, 20 are described in this paper as new species, and 3 among them are considered as to belong to new genera.
\end{abstract}

\section{INTRODUCTION}

The chironomidae of Indonesia (formerly, the Malayan Subregion of the Dutch East Indies) were reported by Johannsen (1932a, b, c), who described 21 species (including 9 new species) of Tanypodinae, 19 species of Orthocladiinae (9 new species), and 62 species of Chironominae (27 new species) from this region. A part of their pupae or larvae were described by Zavrel (1934) and Lenz (1937). Kieffer (1912, 1916, 1921, 1922) described the chironomid species collected in Taiwan and the Philippines, and Tokunaga (1936, 1938, 1939, 1940) described species found in Taiwan. These represented the only references on the Chironomidae of

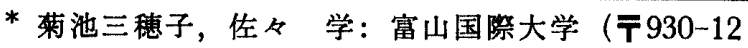
富山県大山町東黒牧) the Southeast Asian region. On the other hand, the information on the Chironomidae of the neighboring regions, such as that referring to Australia was reported by Freeman (1961), to Formosa by Kieffer (1916, 1921, 1922), to Thailand by Hashimoto et al. (1981), to Okinawa by Sasa and Hasegawa (1983, 1988). Recently, a great deal of new information on this group of insects on the mainland of Japan were added by Sasa and his coworkers, as reviewed by Sasa (1989a).

Lake Toba is the largest lake in Southeast Asia, located in northern Sumatra at latitude of $2.5 \mathrm{~N}$ and $905 \mathrm{~m}$ in altitude, and has a surface area of $1,129.7 \mathrm{~km}^{2}$. The present studies on the chironomid midges breeding in or around this lake were conducted while the senior author was stationed in Asahan as a member of the JICA medical cooperation program to Indonesia. Three times of collections were conducted at the side of 
the lake: January 1987, December 1987, and January 1989. The methods of collection, preservation, mounting on slides, and measurements are the same as described in the review paper by Sasa (1989). The adult chironomids resting on grasses or swarming in the air were collected during daytime with insect net or sucking tubes, and those attracted to light during nighttime were also collected. They were preserved dry in small vials, and were mounted on slide glasses by the methods described by Sasa (1989). As the results, a total of 101 male specimens were examined, and they were classified into 31 species, including 20 new species and 3 new genera. The results have obviously contributed a great deal to the information on the taxonomy and ecology of the family Chironomidae of Southeast Asia. All the specimens studied in the present report are deposited in Toyama University of International Studies.

\section{Taxonomic and morphological notes on the species collected}

\section{Chironomus javanus (Kieffer, 1924) (Fig. 1)}

A male was collected at the side of Lake Toba on Jan. 2, 1989 (No. A 200: 51). Ground color of scutum pale yellow, stripes reddish brown, scutellum yellow, postnotum yellowish brown, abdomen entirely pale yellow; femora and tibiae yellow, tarsi I of all legs largely yellow and with a dark apical ring, II and III each with a proximal and an apical dark ring, IV slightly paler in the middle, $\mathrm{V}$ entirely dark brown (Fig. 1-d). Wing with a dark spot around cross vein $\mathrm{r}-\mathrm{m}$.

Frontal tubercles (Fig. 1-a) large, cylindrical, $30 \mu \mathrm{m}$ long, $9 \mu \mathrm{m}$ in diameter and $18 \mu \mathrm{m}$ apart from each other. BL $5.42 \mathrm{~mm}$,
WL $2.42 \mathrm{~mm}$, AR 3.16, AHR 0.53, ER 0.27, SO 20:21, CL 12, PN 0:0, DM 0, DL 8:8, PA $4: 4$, SC 10, SQ 14, RR 0.27, VR 1.09, R/Cu 1.12, fLR 1.70, mLR 0.67, hLR 0.82, fTR 0.40, fBR 3.1, mBR 3.7, hBR 4.7. Terminal process of front tibia broad and rounded (Fig. 1-b). Both terminal comb scales of middle and hind tibiae with a short spur (Fig. 1-c). Pulvilli well developed. Length of front tarsi I to $\mathrm{V}$ being 168, 90, 68, 80 , and $39 \mu \mathrm{m}$ (front tarsus IV is definitely longer than front tarsus III; Fig. 1-d).

Hypopygium in Fig. 1-e. Anal point constricted in the middle. Dorsal appendage (Fig. 1-f) not expanded distally, rectangularly curved near apex, and with pointed apex. Ventral appendage (Fig. 1-g) stout, with 8 stout and recurved setae on dorsal side and 5 or 6 short setae on ventral side of distal portion. Gonostylus abruptly constricted at about distal $1 / 3$ and with a short apical seta and 4 strong setae on inner side of distal portion.

Remarks. This species was first described by Kieffer (1924) from Buitenzorg, Java, and later by Johannsen (1932) from Lake Ranau, Sumatra, by Tokunaga (1964) from a number of Micronesian islands, by Hashimoto et al. (1981) from Thailand, by Sasa and Hasegawa (1983) from Okinawa, and by Hashimoto (1984) from Shizuoka, Japan. It is morphologically unique among the related chironomid species in that body is largely yellow but tarsi I to IV of all legs have proximal and distal dark rings, dorsomedian setae of scutum are absent, and front tarsus IV is longer than front tarsus III.

\section{Chironomus samoensis Edwards, 1928 (Fig. 2)}

Nine males collected at the side of Lake Toba on Dec. 30, 1987, were studied (No. A $199: 02,03,05-08 ; 200: 24-26)$. Body largely

Fig. 1 Chironomus javanus (Kieffer).

a, frontal tubercles; b, tip of front tibia; c, tip of hind tibia; d, front tarsus $\mathrm{I}$ to $\mathrm{V}$, showing relative length and distribution of dark rings; e, hypopygium, dorsal view, left half; $f$, right dorsal appendage; $\mathrm{g}$, right ventral appendage.

Fig. 2 Chironomus samoensis Edwards.

$a$, frontal tubercles and inner margin of eyes; $b$, abdominal tergites, showing distribution of dark areas; c, hypopygium, left half, dorsal view; d, dorsal appendage; e, ventral appendage, dorsal view; f, do., ventral view. 


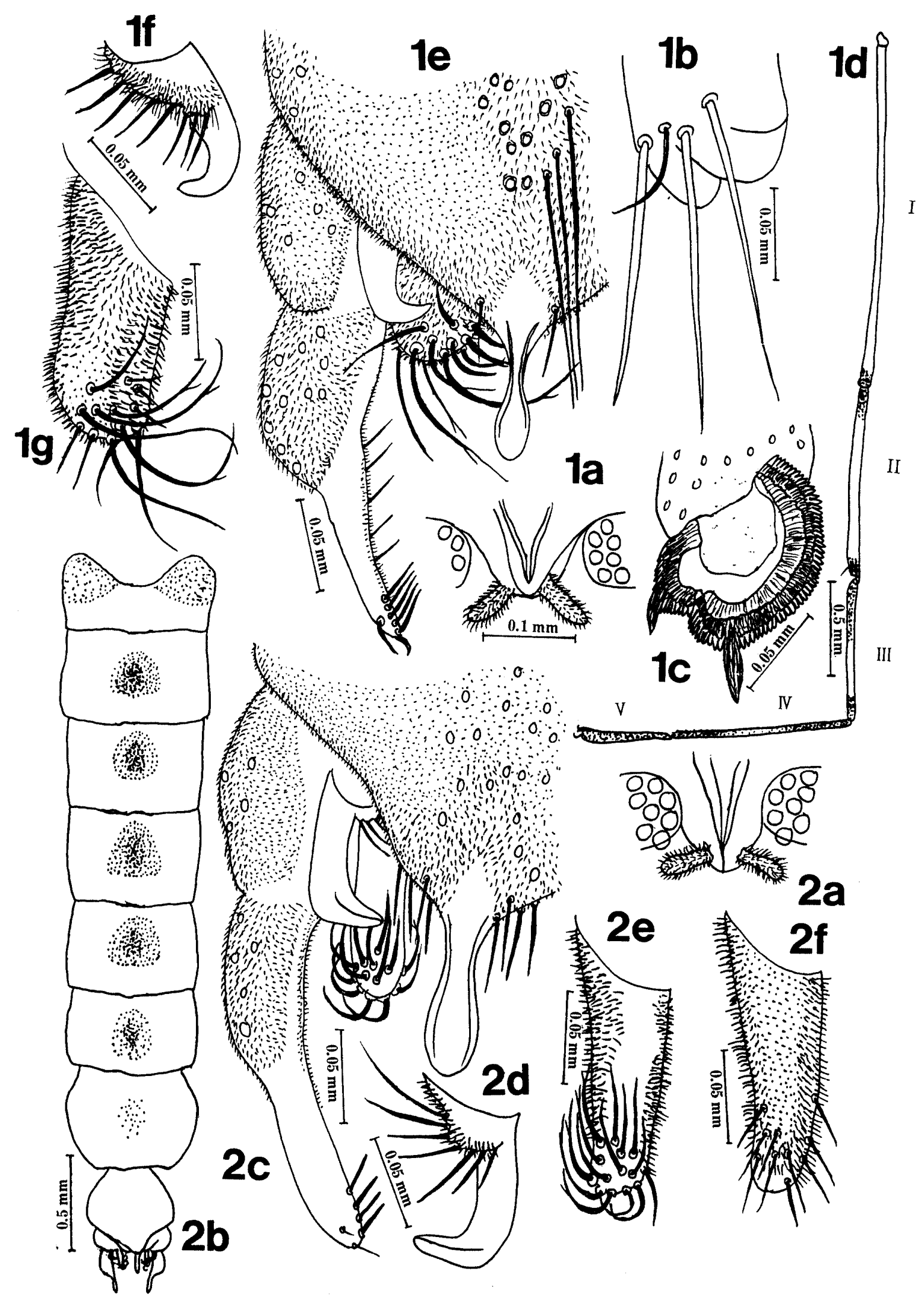

Figs. 1 and 2 
yellow, with brown marks; ground color of scutum yellow, stripes reddish brown, scutellum yellow, postnotum brown, abdominal tergites (Fig. 2-b) II to VI each with an oval dark spot in the middle; leg segments largely yellow, tarsi I and II of all legs with an apical dark ring. BL 5.34-6.34 (5.76 in average of 9) mm, WL 2.36-2.86 (2.56) mm, AR 3.16-3.43 (3.31), AHR 0.53-0.60 (0.55), ER 0.13-0.22 (0.18), SO 26-37 (31.1), CL 12-24 (18.7), PN 0, DM 15-22 (18.7), DL 14-22 (18.1), PA 4-6 (4.7), SG 18-26 (21.4), SQ 15-24 (18.9), RR 0.18-0.29 (0.24), VR 1.05-1.10 (1.07), R/Cu 1.101.14 (1.12), fLR 1.81-1.95 (1.91), mLR 0.65-0.69 (0.67), hLR 0.82-0.88 (0.85), fTR 0.41-0.45 (0.43), fBR 2.5-2.7 (2.6), mBR 2.9-4.1 (3.5), hBR 3.0-5.1 (4.1). Pulvilli well developed. Frontal tubercles long and cylindrical (Fig. 2-a).

Hypopygium in Fig. 2-c. Anal point relatively short and constricted in the middle. Dorsal appendage (Fig. 2-d) roughly Lshaped or boot-like, with a basal setigerous expansion bearing 4-6 long inner setae. Ventral appendage (Fig. 2-e, f) finger-like, with 14-16 recurved setae on dorsal side and 8-19 short, caudally directed setae on ventral side of the distal portion. Gonostylus abruptly constricted in the middle, with a short apical seta and 4 short setae along inner margin of distal portion.

Remarks. The above morphological characters of the present specimens fit to the original description of C. samoensis by Edwards (1928) from Samoa, Tokunaga (1964) from Micronesia, Sasa and Hasegawa (1983) from Okinawa, and Sasa $(1978,1989)$ from various localities in the mainland of Japan, and this species seems to be widely distributed in the Oriental region. Especially characteristic are the presence of oval dark spots on abdominal tergites II to VI, and the high value of fTR (about 0.40), which allow differentiation from the related species, such as C. yoshimatsui Martin et Sublette, 1972.

\section{Dicrotendipes flexus (Johannsen, 1932) (Fig. 3)}

A male was collected at "Samosil" on January 1, 1987 (No. A 200:08). BL 3.76 $\mathrm{mm}$, WL $1.80 \mathrm{~mm}$. Ground color of scutum and scutellum pale yellow, scutal stripes and postnotum brownish yellow, abdomen pale yellow; front femur largely yellow and with a narrow apical dark ring, front tibia and tarsi entirely dark brown; in the middle and hind legs, femora and tibiae yellow, tarsi brown. Frontal tubercles (Fig. 3 -a) very small, $4 \mu \mathrm{m}$ wide, $3 \mu \mathrm{m}$ high and $33 \mu \mathrm{m}$ apart from each other. Eyes each with a long dorsomedial projection, ER 0.22. Antenna with 11 flagellar segments, AR 2.05, AHR 0.56. Palp well developed, with 4 flagellar segments. SO 18:20, CL 16, PN 0.0, DM 10, DL 8:8, PA $3: 4$, SC 8 in a transverse row. Wing bare, SQ 8:8, RR 0.32, VR 1.15, R/Cu 1.09. Front tibia with a semicircular terminal process. Middle and hind tibiae with two terminal comb scales, both with a short spur. fLR 1.80, mLR 0.690, hLR 0.66, fTR 0.31, fBR 2.3, mBR 2.6, hBR 5.3. Pulvilli well developed.

Hypopygium in Fig. 3-b. Anal point short, conspicuously constricted at the base and apically expanded, with 4 pairs of setae on dorsal side and 3 pairs of setae on ventral side near the base. Dorsal appendage (Fig. 3-c) somewhat $L$ shaped, with a conspicuous

Fig. 3 Dicrotendipes flexus (Johannsen).

a, frontal tubercles and inner margin of left eye; b, hypopygium; c, dorsal appendage; d, ventral appendage.

Fig. 4 Tobachironomus tobaprimus, gen. et sp. nov.

a, antepronotum; b, tip of front tibia; c, tip of middle tibia; d, tip of hind tibia; e, hypopygium, dorsal view; f, hypopygium, ventral view; $\mathrm{g}$, h, left and right dorsal appendages; i, ventral appendage, dorsal view.

Fig. 5 Cladopelma viridula (Linnaeus). a, hypopygium; b, anal point, ventral view.

Fig. 6 Cryptochironomus albofasciatus (Staeger). a, hypopygium; b, anal point, ventral view; c, d, left and right dorsal appendage, dorsal view; e, f, ventral and dorsal appendages, left and right, ventral view. 


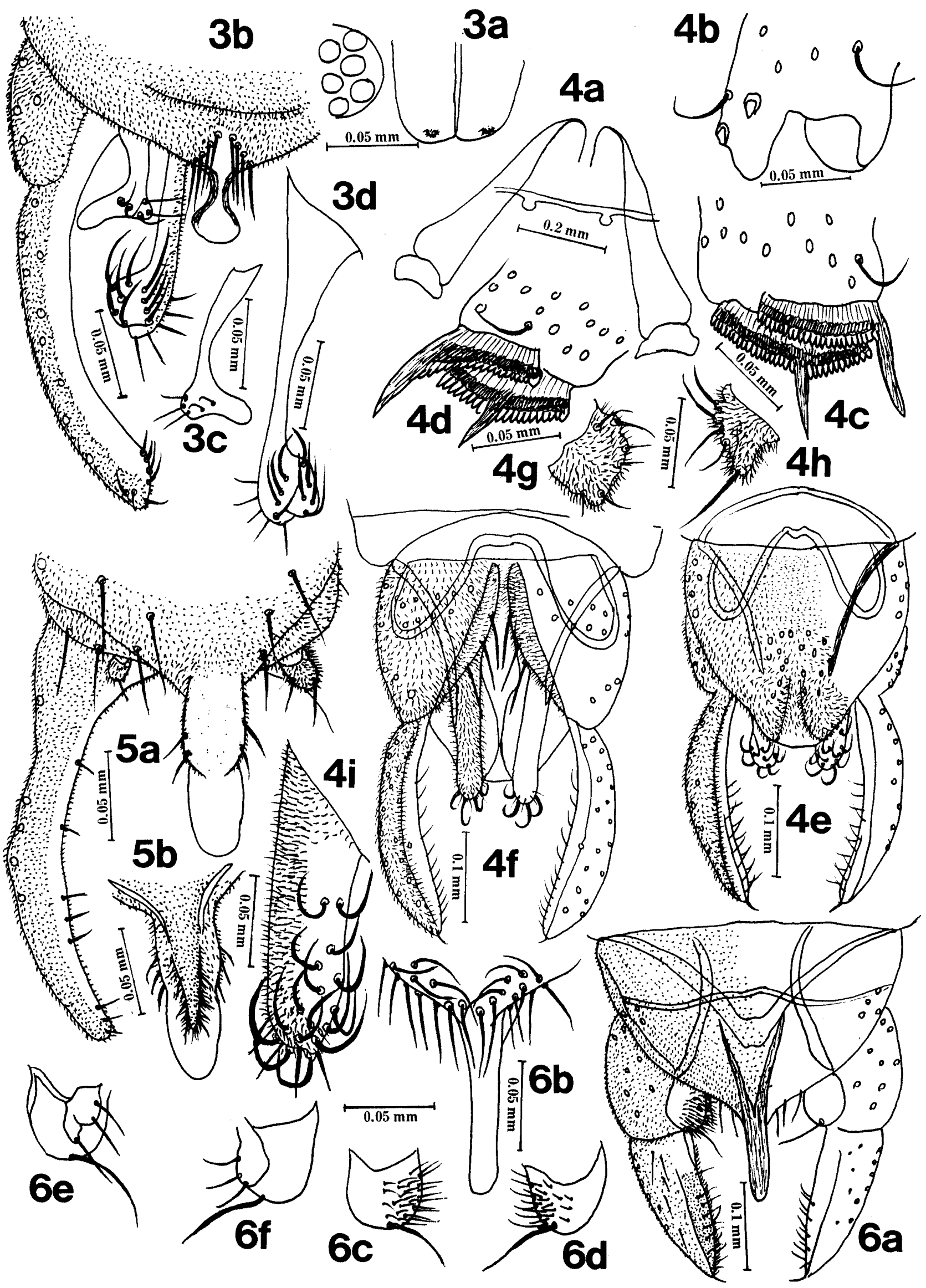

Figs. 3-6 
laterally directed apical process bearing 5 short setae, otherwise bare. Ventral appendage (Fig. 3-d) very long, nearly straight and apically expanded, with 9 recurved setae on dorsal side and 5 nearly straight setae on the apical portion. Gonostylus nearly parallel-sided and smoothly curved, with 5 short setae on inner side of apical portion.

Remarks. The above morphological characters of the present specimen are almost identical with that of Chironomus (Limnochironomus) flexus Johannsen, 1932, described with specimens reared from a larva from River Bedali, Java, and another larva from Lake Ranau, South Sumatra. On the other hand, the specimens described by the name of Dicrotendipes flexus (Johannsen, 1932 ) by Sasa (1985b) from Lake Unagi (Kagoshima) and Lake Shoji (Yamanashi) of Japan are different from the present specimens especially in the shape of dorsal appendage (only slightly expanded apically), and seems to represent another new species.

\section{Tobachironomus, gen. nov.}

A genus of the tribe Chironomini, subfamily Chironominae, and is structurally somewhat between the Chironomus complex and the Harnischia complex. Antenna with 11 flagellar segments. Antepronotum narrowly separated in the middle, without lateral setae. Terminal structure of tibiae as in Chironomus, terminal scale of front tibia wide and rounded, both terminal comb scales of middle and hind tibiae with a spur. Wing unmarked, $\mathrm{R} 2+3$ ending midway between $\mathrm{R} 1$ and $\mathrm{R} 4+5$. Ninth tergite without anal point, and with rounded posterior margin. Dorsal appendage small, pad-like, and bearing numerous microtrichiae and several short setae. Ventral appendage as in Chironomus, well developed, finger-like and with strong recurved setae but without the long, caudally directed apical seta such as seen in Polypedilum.

Type species. Tobachironomus tobaprimus, sp. nov., monotypic.

Remarks. This genus is related to other genera of the Chironomus complex of the tribe Chironomini, in the structure of antenna, wing, legs, and the ventral appendage, but is quite unusual in that anal point is absent and dorsal appendage is small, setigerous and pad-like.

\section{Tobachironomus tobaprimus, sp. nov. (Fig. 4)}

Two males were collected at the side of Lake Toba on Jan. 2, 1989. Holotype: No. A 199:44. Paratype: No. A 199:45. BL 4.24, $4.70 \mathrm{~mm}$, WL 2.18, $2.44 \mathrm{~mm}$. Antennal shaft and hairs dark brown. Ground color of scutum pale yellow, stripes reddish brown, scutellum pale yellow, postnotum brown. Abdominal tergites almost uniformly yellow, hypopygium brownish. Wing membrane unmarked, slightly bluish. All femora and tibiae yellow, front tarsi dark brown, middle and hind tarsi I largely yellow and gradually darkened towards tip, tarsi II to $\mathrm{V}$ brown.

Eyes bare, ER 0.25, 0.12. Antenna with 11 flagellar segments, AR 2.78, 2.95, AHR $0.51,0.53$. SO 20:20, 18:16, CL 15, 21. Antepronotum (Fig. 4-a) narrowly separated in the middle, without lateral setae. DM 22, 24, DL 10:10, 14:14, PA 6:6, 6:7, SC 16, 18. Wing bare and without dark marks. Squama with $8: 12,12: 14$ fringe hairs. $\mathrm{R} 2+3$ ending about midway between tips of $\mathrm{R} 1$ and R4+5, RR 0.50, 0.51 (in most Chironomus species, this value is around 0.2 ). VR 1.11, $1.05, \mathrm{R} / \mathrm{Cu} 1.04,1.10$. Terminal scale of front tibia (Fig. 4-b) broad and rounded. Terminal comb scales of middle and hind tibiae (Fig. 4-c, d) with two relatively long spurs. fLR 1.47, 1.43, mLR 0.61, 0.62, hLR $0.68,0.69$, fTR $0.25,0.23$ (relatively small), fBR 1.9, 1.9, mBR 2.2, 3.3, hBR 3.2, 4.4. Pulvilli well developed, both fan-like.

Hypopygium in Fig. 4-e, f. Ninth tergite with 20, 18 long setae in the central portion, with rounded posterior margin, and without anal point. Ninth sternite with a pair of large lobes, both touching in the middle. Dorsal appendage (Fig. 4-g, h) completely hidden behind ninth tergite, small, pad-like, with several short setae and numerous microtrichiae. Ventral appendage (Fig. 4-i) well developed, the Chironomus type but also hidden largely behind ninth tergite, and with $15: 15,11: 12$ recurved setae on dorsal side and 3 short setae on ventral side of apical portion. Gonostylus long, slender, widest at about middle, and with concave inner mar- 
gin, and bearing two rows of short setae on inner margin.

Remarks. This species is quite unique in the absence of anal point, and in the structure of ninth tergite and dorsal appendage, as pointed out in the definition of this new genus.

\section{Cladopelma viridula (Linnaeus, 1767) (Fig. 5)}

A male was collected at Asahan Dam on Jan. 3, 1989 (No. A 200:84). BL 3.12 mm, WL $1.34 \mathrm{~mm}$. Ground color of scutum pale yellow, stripes reddish brown, scutellum pale yellow, postnotum brown, abdomen pale yellow; all femora yellow, tibiae and tarsi brownish yellow. Frontal tubercles rather prominent, nearly globular, $9 \mu \mathrm{m}$ high, $6 \mu \mathrm{m}$ wide, and $15 \mu \mathrm{m}$ apart from each other. Eyes bare, ER 0.27. Antenna with 11 flagellar segments, AR 2.14, AHR 0.60. Palp with 5 flagellar segments, $365 \mu \mathrm{m}$ long in total and 0.82 times as long as the width of head. SO 6:6, CL 10, PN 0:0, DM 2, DL 6:6, PA $3: 3$, SC 4, SQ 3:5. Wing bare, finely granular, without dark marks. RR 0.22 , VR 1.25, R/Cu 1.09. Terminal scale of front tibia broad and rounded. Terminal comb scales of middle and hind tibiae both with a short spur. Front tarsi broken off. mLR 0.53, hLR 0.67, mBR 4.5, hBR 4.7. Pulvilli well developed.

Hypopygium in Fig. 5-a. Anal point broad and apically rounded, with short lateral setae on basal half, distal half hyaline, and with microtrichiae and a few short seta on ventral side (Fig. 5-b). Ninth tergite with several setae on both sides of anal point but without long setae in the central region. Dorsal appendage very small, pad-like, with a short terminal seta and covered thickly by microtrichiae. Ventral appendage absent. Gonostylus ankylosed with gonocoxite, long, slender and widest at about basal $1 / 3$.

Remarks. The above morphological characters of this specimen fit roughly to the description of Cladopelma viridula (Linnaeus, 1767) of Edwards (1929), Goetghebuer (1937) and Pinder (1978) from Europe, Townes (1945) from North America, Hashimoto et al. (1981) from Thailand, Sasa and Hasegawa (1983) from Okinawa, and Sasa
(1985) from southern Kyushu.

\section{Cryptochironomus albofasciatus (Staeger, 1840) (Fig. 6)}

A male was collected at Asahan Dam on Jan. 3, 1989 (No. A 200:85). BL $4.28 \mathrm{~mm}$, WL $2.24 \mathrm{~mm}$. Ground color of scutum pale, stripes brownish yellow, scutellum pale yellow, postnotum brown, abdominal tergites yellow, hypopygium yellowish brown; all femora yellow, front tibia dark brown, other tibiae yellow, middle and hind tarsi I-III yellow, IV and V brown. Eyes bare, ER 0.07. Antenna with 11 flagellar segments, AR 2.71, AHR 0.57. SO 22:22, CL 22, PN $10: 10$, DM 16, DL 12:11, PA 6:6, SC 16, SQ 14:16, RR 0.28, VR 1.10, R/Cu 1.12. Terminal scale of front tibia broad and rounded. Terminal comb scales of middle and hind tibiae both with a spur. Front tarsi broken off. mLR 0.72 (unusually high), hLR 0.76, mBR 3.3, hBR 4.0. Pulvilli well developed.

Hypopygium in Fig. 6-a. Anal point relatively long, slender and parallel-sided. Bands of ninth tergite united in the middle, Vshaped. Ninth tergite without long setae in the central region. Ninth sternite with numerous strong setae at the base of anal point (Fig. 6-b). Dorsal appendage (Fig. 6-c,d) pad-like and roughly semicircular, $20 \mu \mathrm{m}$ long and $19 \mu \mathrm{m}$ wide, with one terminal seta and numerous microtrichiae. Ventral appendage (Fig. 6-e,f) small, $23 \mu \mathrm{m}$ long and $16 \mu \mathrm{m}$ wide, completely hidden behind dorsal appendage, and with 3 short setae but without microtrichiae. Gonostylus ankylosed with gonocoxite, widest at base and tapering towards pointed apex.

Remarks. The above morphological characters, especially the structure of anal point, dorsal and ventral appendages, as well as the shape of gonostylus are coincident with the description of $C$. albofasciatus by Sasa and Kawai (1987) from Lake Biwa, Japan. However, as pointed out in this paper, this is a species originally described from Europe, and further comparative studies are needed in order to determine whether this and the Japanese specimens are identical with those described by various authors from Europe. 


\section{Cryptotendipes tobasecundus, sp. nov. (Fig. 7)}

A total of 8 males were collected and identified, a male at the side of Lake Toba on Jan. 1, 1987 (No. A 200:12), and 7 males at the side of Asahan Dam on Jan. 3, 1989 (No. A 199:26-28, 200:81-84). Holotype: No. A 200:81. Paratypes: other males. BL 2.72-3.36 (3.02 in average of 8$) \mathrm{mm}$, WL 1.26-1.46 (1.34) mm. Ground color of scutum pale yellow, stripes reddish brown, scutellum pale yellow, postnotum brown (dark brown in the central portion), abdominal tergites entirely yellow; in the front leg, femur yellow, tibia brown, basal half of tarsus I yellow and gradually darkened towards tip, tarsi II to V dark brown; in the middle and hind legs, distal half of tarsi III brown, tarsi IV and $\mathrm{V}$ dark brown, the proximal parts yellow.

Eyes bare, ER 0.29-0.43 (0.37). Antenna with 11 flagellar segments, AR 1.65-2.00 (1.81), AHR 0.50-0.56 (0.53). Frontal tubercles absent. SO 8-10 (9.0), CL 11-16 (13.4). Antepronotum (Fig. 7-a) thickly united in the middle, and with 2-5 (3.4) lateral setae. DM 3-6 (mean 4.5, unusually small), DL 5-9 (6.7), SC 4-8 (5.5). Wing membrane bare, smooth and slightly bluish. Squama with 5-9 (6.7) fringe hairs. RR 0.32-0.48 (0.38), VR 1.11-1.21 (1.15), R/ $\mathrm{Cu}$ 1.05-1.11 (1.08). Front tibia with rounded terminal scale (Fig. 7-b). Both comb scales of middle and hind tibiae with a short spur (Fig. 7-c). fLR 1.59-1.70 (1.65), mLR 0.54-0.60 (0.56), hLR 0.620.68 (0.65), fTR $0.78-0.32(0.30)$, fBR 2.22.7 (2.3), mBR 2.4-2.8 (2.6), hBR 2.8-3.5 (3.1). Pulvilli well developed, fan-like.

Hypopygium in Fig. 7-d. Anal point long, slender, parallel-sided or slightly constricted in the middle. Ninth tergite with short setae at the base of anal point but without long setae in the central portion. Ninth sternite (Fig. 7-e) with 6 or 7 setae at the base of anal point, and a pair of lobes each bearing 3 strong setae. Dorsal appendage (Fig. 7-f) relatively long, rod-like and bearing 3 or 2 short setae but without microtrichiae. Ventral appendage absent. Gonostylus long, slender, nearly parallel-sided and with concave inner margin, slightly expanded near the base.

Remarks. This species is designated as a member of genus Cryptotendipes Lenz, 1941, in the sense of Pinder (1978), since it is a member of the Harnischia-complex of the tribe Chironomini, dorsal appendage is rodlike and bearing a few short setae, ventral appendage is absent, gonostylus is long, incurved but not much swollen basally and without apical tooth, and without processes on both sides of anal point such as seen in the genus Microchironomus Kieffer, 1918 (=Leptochironomus Pagast, 1931). Saether (1977, p. 95) reviewed this genus and gave key to previously known 10 species, among which the present species is most closely related to $C$. emorsus (Townes, 1945) in that ninth tergite without dorsal hump, inner margin of gonostylus is concave in apical half, anal point is longer than dorsal appendage, and dorsal appendage has no microtrichiae. However, $C$. emorsus differs from the present species in that gonostylus is sharply produced inwards and apically truncate (ref. Fig. 34A, p. 96, Saether, 1977). Among the three species of this genus known from Japan, this species is most closely related to C. oyabeprimus Sasa et al., 1988, but the latter is larger in body size (WL $1.76 \mathrm{~mm}$ ), higher in AR (2.30) and fLR (2.09), with frontal tubercles which are absent in the present species, with 10 long setae on ninth

Fig. 7 Cryptotendipes tobasecundus, sp. nov.

$\mathrm{a}$, antepronotum; b, tip of front tibia; c, tip of hind tibia; d, hypopygium, dorsal view; e, anal point, ventral view; $f$, right dorsal appendage.

Fig. 8 Cryptotendipes tobatertius, sp. nov.

a, tip of front tibia; b, tip of hind tibia; $c$, hypopygium, dorsal view; d, hypopygium, ventral view.

Fig. 9 Microchironomus tener (Kieffer).

a, frontal tubercles; b, tip of front tibia; c, tip of hind tibia; d, hypopygium, dorsal view; e, hypopygium, ventral view. 


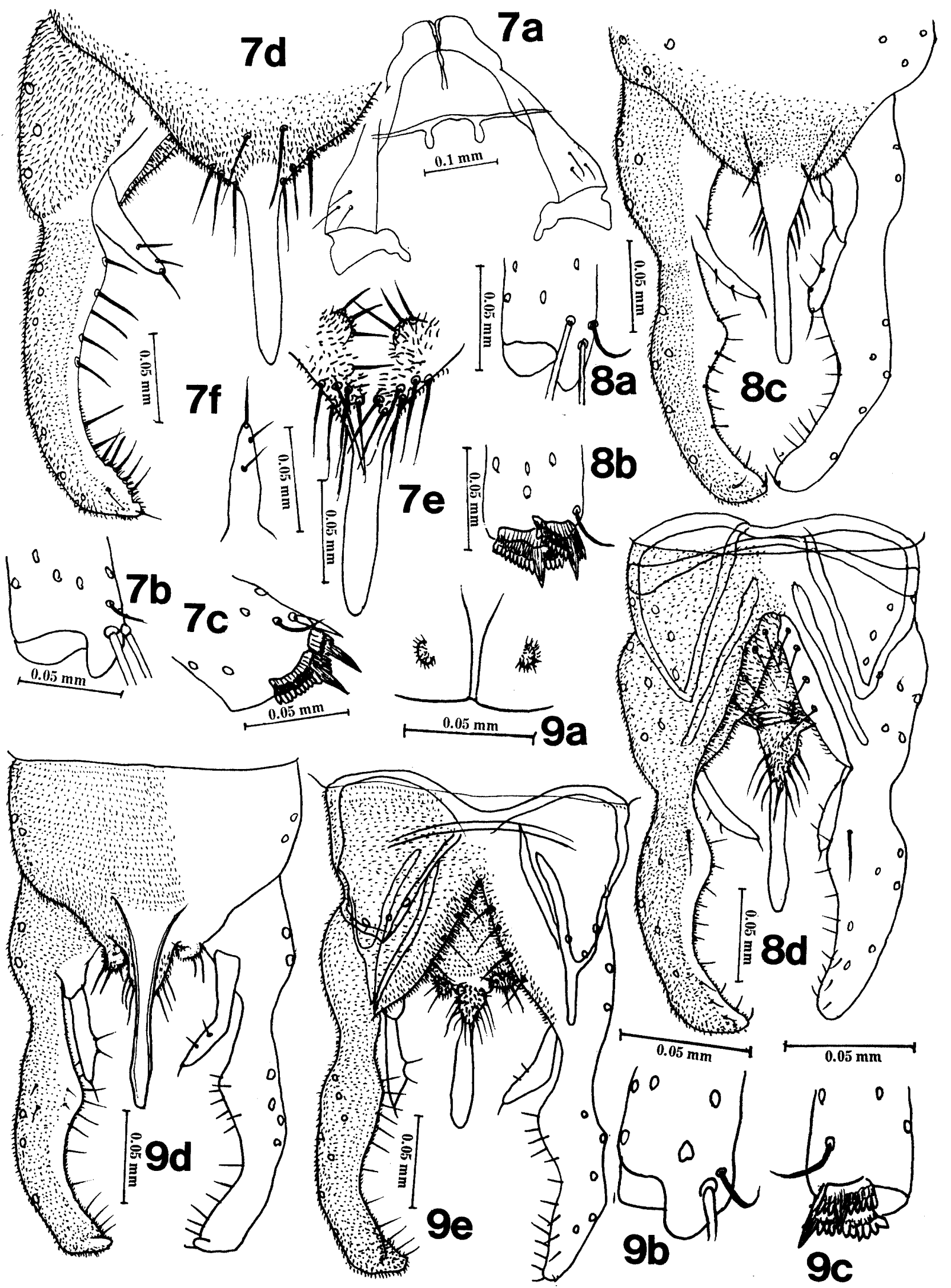

Figs. 7-9 
tergite at the base of anal point (only 2 in the present species), and has longer dorsal appendage.

\section{Cryptotendipes tobatertius, sp. nov. (Fig. 8)}

A male (holotype) was collected at the side of Lake Toba on Jan. 1, 1989 (No. A $200: 58)$. BL $2.66 \mathrm{~m}$, WL $1.09 \mathrm{~mm}$, both smaller than in the preceding speices. Body largely pale yellow, ground color of scutum pale, stripes yellowish brown, scutellum pale, postnotum dark brown, abdominal tergites pale yellow; leg segments almost entirely pale yellow, without dark rings such as seen in the preceding species. Wing unmarked.

Eyes bare, ER 0.32. Small frontal tubercles present. Antenna with 13 flagellar segments, AR 1.58, AHR 0.50. Palp with 4 flagellar segments, 33, 86, 95, $90 \mu \mathrm{m}$ long, $257 \mu \mathrm{m}$ in total length, shorter than the diameter of the head of $390 \mu \mathrm{m}$. SO $6: 6$, CL 8, PN 2:2, DM 4, DL 8:8, PA 3:4, SC 6, SQ 8. Wing membrane bare, smooth and brownish. RR $0.46, \mathrm{VR} 1.14, \mathrm{R} / \mathrm{Cu}$ 1.08. Tip of front tibia (Fig. 8-a) with a long and rounded scale. Terminal combs of middle and hind tibiae (Fig. 8-b) both with a short spur. fLR 1.84, mLR 0.65, hLR 0.71 (all larger than in the preceding species), fTR 0.35 , fBR 3.0, mBR 2.8, hBR 3.0. Pulvilli well developed.

Hypopygium in Fig. 8-c, d. Ninth tergite acutely angular in the middle, and without long setae in the central portion. Anal point very long, widest at base, tapering towards middle and parallel-sided for the distal half, with long setae on lateral and ventral side of the middle portion. Dorsal appendage very long and slender, $47 \mu \mathrm{m}$ long and $7 \mu \mathrm{m}$ wide, with one short apical seta and two short distal setae. Ventral appendage absent. Inner margin of gonostylus conspicuously expanded at about basal $1 / 3$, and strongly concave distally.

Remarks. This is again a typical member of genus Cryptotendipes, and similar in morphological characters to the preceding species, but can be differentiated by that body coloration is generally paler, without dark rings on legs, anal point is much longer and widest at base, and inner margin of gonostylus has a strong expansion and is more strongly concave.

\section{Microchironomus tener (Kieffer, 1918) (Fig. 9)}

Four males were collected at the side of Lake Toba, one on Dec. 30, 1987, and 3 on Jan. 2, 1989 (No. A 199:40, 41, $200: 57,59$ ). BL 2.54-2.72 (2.64 in average of 4), WL $1.14-1.26(1.20) \mathrm{mm}$. Ground color of scutum pale, stripes brownish yellow, scutellum pale, postnotum brown, abdomen entirely yellow; wing unmarked; all femora yellow, front tibia dark brown, front tarsi brown; middle and hind tibiae as well as tarsi I-IV yellow, tarsi $\mathrm{V}$ brown. Eyes bare, ER 0.24$0.33(0.29)$. Antenna with 11 flagellar segments, AR 1.51-1.79 (1.63), AHR 0.45-0.52 (0.49), small frontal tubercles present (Fig. 9-a), $7 \mu \mathrm{m}$ wide, $3 \mu \mathrm{m}$ high, and $30 \mu \mathrm{m}$ apart from each other. SO 6-8 (7.4), CL 8-12 (10.8), PN 2-4 (3.0), DM 6-9 (7.3), DL $6-10(8.3)$, PA $2-3(2.9)$, SG 5 or $6(5.8)$, SQ 6 or 7 (6.7), RR 0.27-0.42 (0.36), VR 1.16-1.20 (0.18), R/Cu 1.04-1.07 (1.06). Terminal process of front tibia (Fig. 9-b) broad and rounded. Terminal comb scales of middle and hind tibiae (Fig. 9-c) both with a short spur. fLR 1.82-2.02 (1.92), mLR 0.65-0.70 (0.67), hLR 0.69-0.76 (0.72), fTR $0.32-0.34(0.33)$, fBR 2.1-3.6 (2.6), mBR 2.6-3.7 (3.1), hBR 3.1-4.6 (3.7). Pulvilli well developed.

Hypopygium in Fig. 9-d, e. Anal point very long, slender, widest at base and slightly constricted in the middle, with a tubercle on ventral side of the base, bearing several setae and numerous microtrichiae. Ninth tergite with a pair of low tubercles on posterior margin near the base of anal point, which bears several strong setae and numerous microtrichiae, but without long setae in the central region. Dorsal appendage relatively long and slender, without microtrichiae and with 3 short setae. Ventral appendage absent. Gonostylus ankylosed with gonocoxite, long, strongly incurved and swollen basally, and with an apical tooth.

Remarks. These specimens are considered as to belong to the genus Microchironomus Kieffer, 1918 (=Leptochironomus Pagast, 1931), since dorsal appendage is rod-like and bearing a few setae but without microtrichiae, 
ventral appendage is absent, ninth tergite with a pair of setigerous tubercles flanking anal point, and gonostylus is swollen basally, strongly incurved and with an apical tooth. This genus was reviewed by Saether (1977), who recognized 4 species within this genus, among which the present species is almost coincident with the description of $M$. tener (Kieffer, 1918). Three species, including this and two new species, were recorded by Sasa and Kawai (1987) from Japan. Chironomus (Cryptochironomus) primitivus Johannsen, 1932, recorded from Java, was regarded as a synonym of $M$. tener by Saether (1977).

\section{Parachironomus tobaquartus, sp. nov. (Fig. 10)}

Three males were collected, one at Samosil on Jan. 1, 1987 (holotype, No. A 200:06), one at Lake Toba on Jan. 2, 1989, another at Asaham Dam on Jan. 3, 1989 (paratypes, No. A 200:53, 79). BL 3.40, 3.52, $3.72 \mathrm{~mm}$, WL 1.55, 1.61, $1.65 \mathrm{~mm}$. Ground color of scutum pale, stripes brownish yellow, scutellum pale yellow, postnotum brownish yellow, abdominal tergites yellow; all femora yellow; front tibia dark brown, other tibiae yellow; all tarsi I basally yellow and gradually darkened towards tip, front tarsi II-V dark brown, middle and hind tarsi II-IV brown, $\mathrm{V}$ dark brown.

Frontal tubercles (Fig. 10-a) small, $2 \mu \mathrm{m}$ high, $4 \mu \mathrm{m}$ wide, and $22 \mu \mathrm{m}$ apart from each other. Antenna with 11 flagellar segments, AR 1.95, 2.05, 2.18, AHR 0.53, 0.54, 0.55. Palp with 5 flagellar segments, segment I with one seta, each $32,55,120,164,237 \mu \mathrm{m}$, and $590 \mu \mathrm{m}$ in total length, or 1.08 times as long as the width of head. SO $14: 15,16: 16$, $18: 20$, CL 4, 4, 6 (unusually small in number). Antepronotum well developed, PN $3: 4$, $3: 4$, 6.6. DM 12, 12, 14, DL $11: 11,10: 12$, $13: 13$, PA $4: 4,4: 4,4: 5$, SC 10, 16, 17 . Squama with $5: 7,7: 9,13: 15$ fringe hairs. Wing membrane bare, finely granular and without dark marks. RR $0.26,0.33,0.33$, VR 1.14, 1.18, 1.19, R/Cu 1.06, 1.07, 1.09. Terminal scale of front tibia (Fig. 10-b) broad and rounded, with two subterminal setae. Both terminal comb scales of middle and hind tibiae with a short spur (Fig. 10-c, d). fLR 1.95, 2.02, $\operatorname{mLR} 0.73,0.73,0.74$,
hLR $0.75,0.76,0.77$, fTR $0.33,0.34$, fBR 1.6, 2.3, mBR 2.3, 2.5, 2.8, hBR 2.6, 3.2, 3.3. Pulvilli well developed.

Hypopygium in Fig. 10-e, f. Anal point broad, almost parallel-sided and with rounded apex, with a pair of narrowly separated ridge in the middle. Ninth tergite with 8 short setae on each side of anal point, but without long setae in the central region. Dorsal appendage (Fig. 10-g) relatively small and narrow, rod-like and with 2 or 3 short setae but without microtrichiae. Ventral appendage (Fig. 10-h) small, pad-like and oval in shape, almost entirely covered with microtrichiae and with 3 short marginal setae. Gonostylus ankylosed with gonocoxite, inner margin slightly convex.

Remarks. This species is a member of genus Parachironomus Lenz, 1921, of the Harnischia complex of the tribe Chironomini, 1921, since both dorsal and ventral appendages are reduced, dorsal appendage is rodlike and bearing a few setae, and ventral appendage is a small pubescent pad (Pinder, 1978 , p. 104). Altogether 17 species were recorded by Lehmann (1970) from Europe, 9 species by Pinder (1978) from Great Britain and 2 species by Sasa. (1989) from Japan as members of this genus, but anal point of all of these species are very long and narrow, not wide and stout as in the present species.

\section{Microtendipes tobaquintus, sp. nov. (Fig. 11)}

Four males were collected at the side of Lake Toba on Jan. 2, 1989 (holotype: No. A 199:42: paratypes: No. A 199:43, 200:54, 52). BL 3.76-4.88 (4.46 in average of 4) $\mathrm{mm}$, WL 2.00-2.58 (2.35) $\mathrm{mm}$. Ground color of scutum pale, median stripes largely yellowish brown and dark brown along lateral margin, lateral stripes dark brown excepting narrow yellow band along lateral margin; scutellum brown, postnotum dark brown; abdominal tergites yellow, hypopygium brown; wing unmarked; front femur with a median and apical dark brown rings and two pale rings in basal half and in distal $1 / 3$; middle and hind femora largely pale and with a narrow apical dark ring; all tibiae largely pale and with narrow basal and apical 


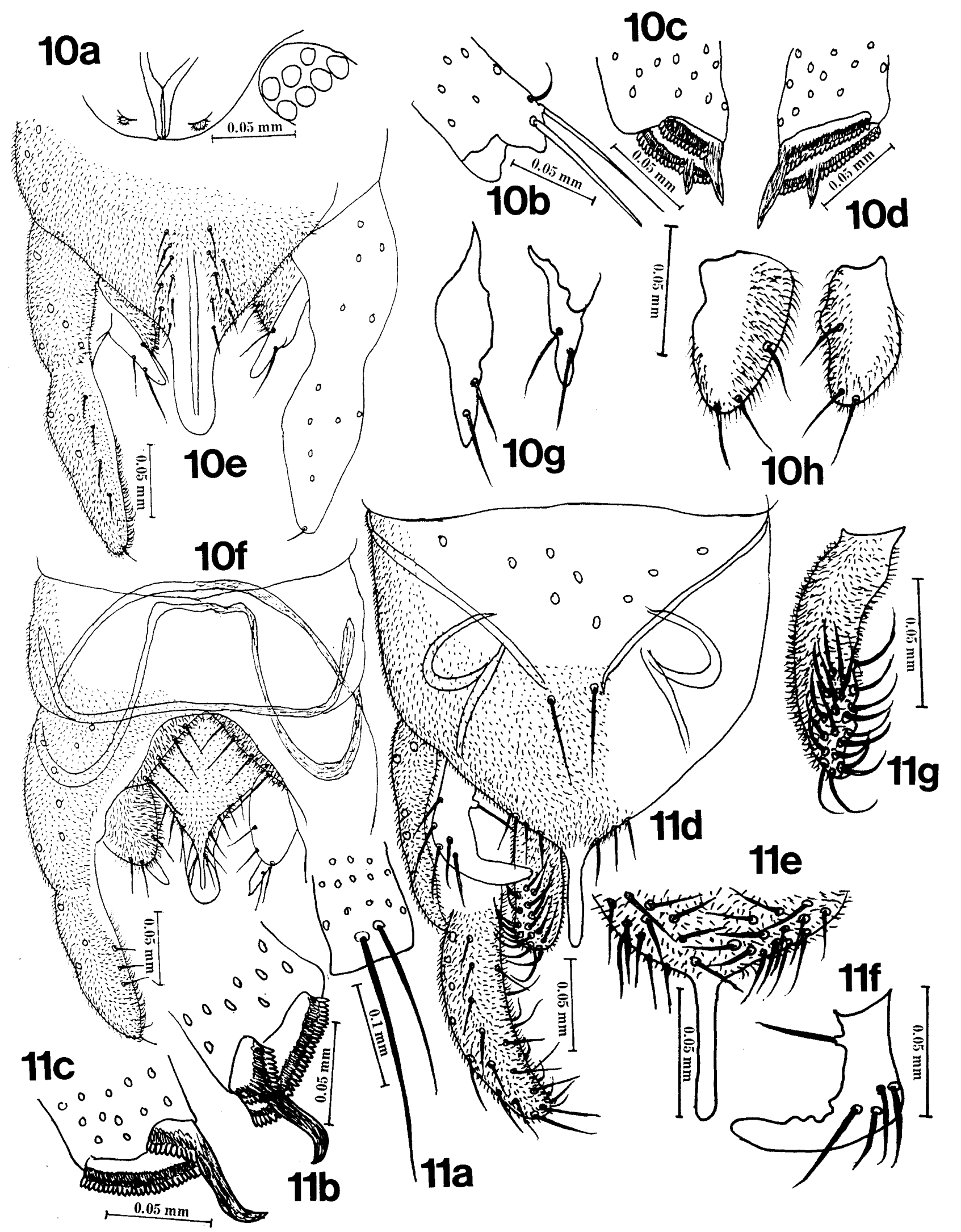

Figs. 10 and 11 
dark rings; front tarsi I, II and III largely pale and each with a narrow apical dark ring, IV and $\mathrm{V}$ entirely brown; tarsi I, II and III of middle and hind legs entirely pale, IV with an apical dark ring, $\mathrm{V}$ entirely brown.

Eyes bare, ER 0.22-0.28 (0.25). Frontal tubercles absent. Antenna with 13 flagellar segments, AR 1.80-2.14 (2.02), AHR 0.520.59 (0.56). Palp well developed, dark brown, $0.80 \mathrm{~mm}$ long and 1.47 times as long as the width of head. SO 18-24 (20.4), CL 17-30 (24.8), PN 0, DM 1-4 (mean 2.5, extremely small), DL 10-13 (11.8), PA 4-5 (4.1), SC 12-23 (16.8), SQ 11-17 (14.8). Wing bare, slightly bluish and finely granular. $\mathrm{R} 2+3$ fused with $\mathrm{R} 1$ along its entire length, RR 0.05-0.09 (0.08). VR 1.09-1.14 (1.12), $\mathrm{R} / \mathrm{Cu}$ 1.10-1.14 (1.12). Tip of front tibia (Fig. 11-a) truncate, without terminal process. Terminal comb scales of middle and hind tibiae (Fig. 11-b, c) with one long and curved spur. fLR 1.19-1.25 (1.22, relatively small as a member of Chironomini), mLR 0.68-0.73 (0.70), hLR 0.83-0.84, fTR 0.21 (very small), fBR 3.2-3.9 (3.6), mBR 3.34.2 (3.9), hBR 4.0-5.4 (4.8). Pulvilli well developed.

Hypopygium in Fig. 11-d. Anal point long, slender and almost parallel-sided. Bands of anal tergite separated in the middle. Ninth tergite with long setae in the basal portion, two setae in the central portion, and 4 short setae on posterior margin flanking anal point. Anal sternite with numerous strong setae at the base of anal point (Fig. 11-e). Dorsal appendage (Fig. 11-f) band-like and rectangularly curved, with one long inner seta near the base, and 4 or 5 setae in the middle and lateral portion. Ventral appendage (Fig. $11-\mathrm{g}$ ) finger-like and with some 20 recurved setae but without long terminal seta. Gonostylus widest at about basal $1 / 3$ and with slightly concave inner margin.

Remarks. This species is a typical mem- ber of genus Microtendipes Kieffer, 1915, since antenna is composed of 13 flagellar segments, vein $R 2+3$ is fused with $R 1$, squama with fringe hairs, front tibia with truncate tip and without terminal scale, one comb of middle and hind tibiae with a long terminal spur, dorsal appendage is band-like, rectangularly curved and with 4 or 5 setae in the middle, ventral appendage is a Chironomus-type and without long apical seta. Among the previously known species of this genus, the present species is somewhat related to $M$. chloris (Meigen, 1818) in that anal point is narrow and parallel-sided, dorsal appendage is narrow, curved and with one inner and 4 or 5 lateral setae, and both gonostylus and ventral appendage are of normal type. However, the present species differs from all the previously known species of this genus in that leg segments have a number of dark rings, middle scutal stripes are paler than the lateral stripes, and abdomen is entirely pale.

\section{Asachironomus, gen. nov.}

A new genus within the Polypedilum complex of Tribe Chironomini, with A. tobasextus sp. nov. as the monotypic species. Antenna with 13 flagellar segments. Squama with a few fringe hairs. Wing membrane unmarked, and with numerous macrotrichiae on almost the entire surface. Cross vein $r-m$ is long and not parallel to wing axis. $\mathrm{R} 2+3$ is ending before united to costa. Terminal comb scales of middle and hind tibiae are fused and without spur. Anal point is stout, hyaline and constricted in the middle. Ninth tergite with numerous long setae in the central region. Dorsal appendage sickle-shaped, with long inner setae on its base, and one long lateral seta in the middle. Ventral appendage finger-like, with recurved setae and one long caudally directed seta. Oral margin of eighth segment not constricted in the mid-

Fig. 10 Parachironomus tobaquartus, sp. nov.

$a$, frontal tubercles and inner margin of right eye; b, tip of front tibia; $c$, tip of middle tibia; $d$, tip of hind tibia; $e$, hypopygium, dorsal view; $f$, hypopygium, ventral view; $g$, left and right dorsal appendages; $h$, left and right ventral appendages.

Fig. 11 Microtendipes tobaquintus, sp. nov.

a, tip of front tibia; b, tip of middle tibia; $c$, tip of hind tibia; d, hypopygium; e, anal point, ventral view; $f$, right dorsal appendage; $g$, right ventral appendage. 
dle like in Popypedilum and Pentapedilum spp.

Remarks. This genus is somewhat related to genera Pentapedilum Kieffer, 1913, and Phaenopsectra Kieffer, 1921 in that wing bears numerous macrotrichiae, antenna has 13 flagellar segments, squama has a few fringe hairs, dorsal appendage is sickle-shaped and with one long lateral seta, and ventral appendage has a long apical seta. However, members of the genus Pentapedilum differ essentially from the present genus in that terminal combs of middle and hind tibiae are separated and one with a long spur and the other without spur, wing vein $\mathrm{R} 2+3$ is complete and ending close to the tip of R1, anal point is long and slender, and gonostylus bears several long setae on distal portion of inner margin. Members of the genus Phaenopsectra differ also from the present genus in that AR is about 2.0, and terminal combs of middle and hind tibiae with two (rarely one) spurs. The generic name is derived from Asahan, the type locality of this new species.

\section{Asachironomus tobasextus, sp. nov. (Fig. 12)}

Five males were collected and identified at the side of Lake Toba, 3 on Jan. 1, 1987 (No. A 199:04, holotype; No. A 199:15, 200:05, 27; paratypes), one on Jan. 2, 1989 (No. A 199:37; paratype).

BL 2.46-2.86 (2.65 in average of 4) mm, WL 1.11-1.33 (1.22) mm. Scutum, scutellum, postnotum and abdominal tergites almost uniformly dark brown, wing unmarked, leg segments uniformly yellowish brown. Eyes bare, ER 0.13-0.21 (0.17). Antenna with 13 flagellar segments, AR 0.53-0.65 (0.61), AHR 0.29-0.38 (0.35). Palp 5 segmented, $27,40,68,90,130 \mu \mathrm{m}$, palp/head ratio 0.86 . SO 6-11 (8.5), CL 12-22 (22.0). Antepronotum with no lateral setae. DM 11-15
(13.0), DL 9-14 (11.0), PA 3 or 4 (3.4), SC 5-9 (6.5). Wing in Fig. 12-a. Squama with 1-4 (3.0) fringe hairs. Wing membrane with numerous macrotrichiae on almost entire surface. $\mathrm{R} 2+3$ separated from both $\mathrm{R} 1$ and $\mathrm{R} 4+5$, but ending before united to costa in all the specimens examined. VR 1.20-1.43 (1.33), R/Cu 1.05-1.07 (1.06). Terminal scale of front tibia (Fig. 12-b) broad and with rounded margin. Terminal comb scales of middle and hind tibiae (Fig. 12-c, d) contiguous, low, broad, and without spur. fLR 1.86-2.00 (1.93), mLR 0.57-0.58, hLR 0.68$0.70(0.69)$, fTR $0.26-0.30(0.28)$, fBR 2.6 3.2 (2.9), mBR 3.7-4.8 (4.3), hBR 5.3-7.9 (6.6). Pulvilli well developed (Fig. 12-e).

Hypopygium in Fig. 12-f, g. Oral margin of 8th tergite V-shaped, as in Pentapedilum and Polypedilum species. Anal point stout, hyaline, constricted in the middle and apically rounded. Ninth tergite with 8-12 long, stout setae in the central portion. Dorsal appendage (Fig. 12-h) sickle-shaped, with 1-3 inner setae at base, and one long lateral seta arising at about distal $1 / 3$. Ventral appendage (Fig. 12-i) the Polypedilum type, with 10-12 recurved setae and a long caudally directed apical seta. Gonostylus stout, widest at about middle, with a broad lobe on ventral side of apical half of inner margin, but without long inner setae such as seen in Polypedilum and Pentapedilum species.

Remarks. This species is somewhat similar in the structure of antenna, wing and hypopygium to species of the genus Pentapedilum Kieffer, 1913, but these can be differentiated from the present species by that one terminal comb scale of middle and hind tibiae has a long spur, and gonostylus has long setae along inner margin.

\section{Polypedilum tobaseptimum, sp. nov. (Fig. 13)}

Nine males were collected at the side of

Fig. 12 Asachironomus tobasextus, gen. et sp. nov.

a, right wing; $b$, tip of front tibia; $c$, tip of middle tibia; $d$, tip of hind tibia; $e$, hind tarsus $\mathrm{V}$; $\mathrm{f}$, abdominal tergite VIII and hypopygium; $\mathrm{g}$, hypopygium, dorsal view; h, dorsal appendage; $\mathrm{i}$, ventral appendage, dorsal view.

Fig. 13 Polypedilum tobaseptimum, sp. nov.

a, frontal tubercles; b, wing; c, tip of front tibia; d, tip of middle tibia; e, tip of hind tibia;

$\mathrm{f}$, hypopygium; $\mathrm{g}$, right dorsal appendage; $\mathrm{h}$, right ventral appendage. 


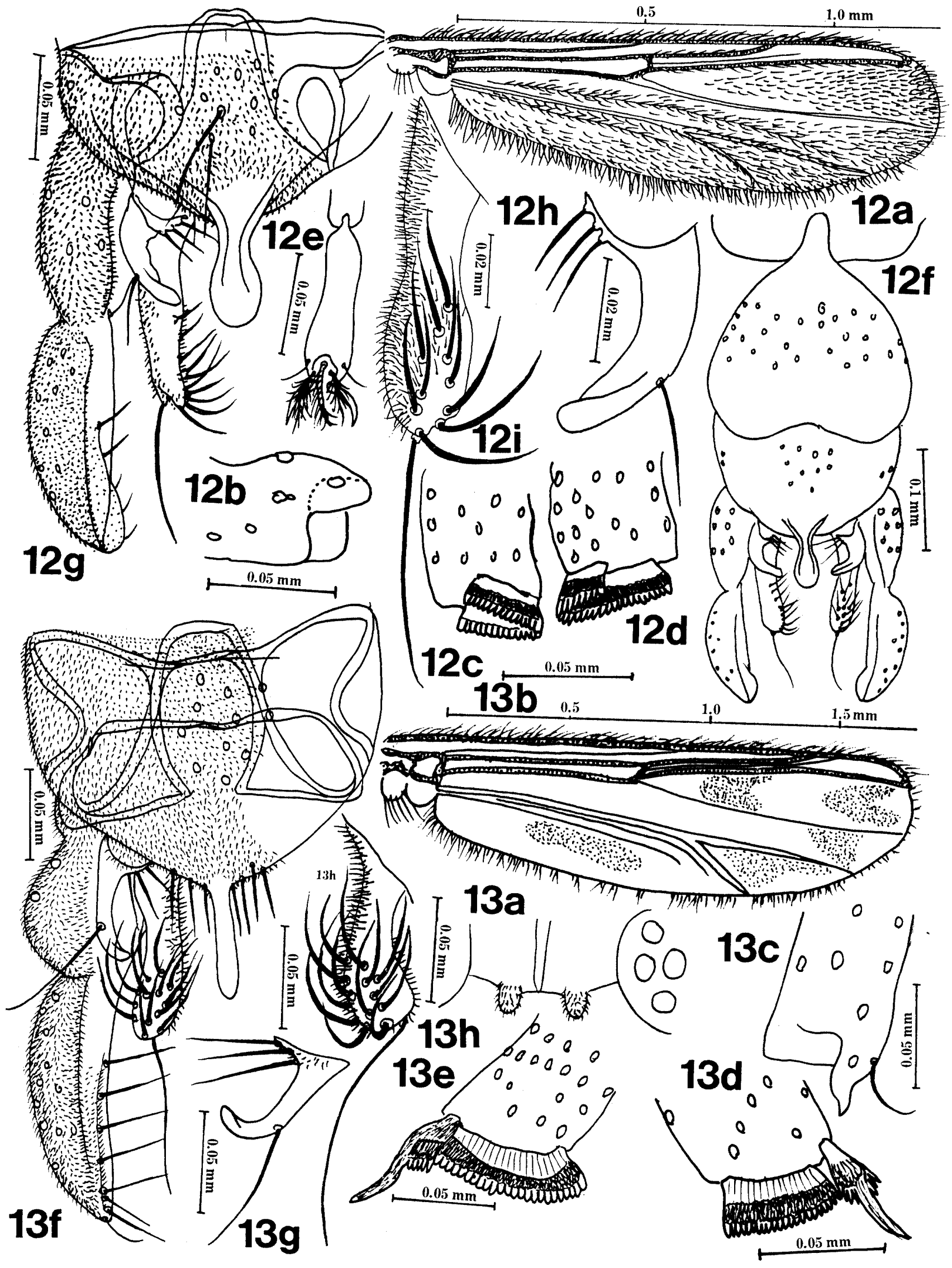

Figs. 12 and 13 
Lake Toba on Jan. 2, 1989. Holotype: No. A 200:66. Paratypes: No. A 199:34-36, 200: 30-32, 64, 65. BL 3.30-3.74 (3.59 in average of 9) mm, WL 1.59-1.75 (1.70) mm. Body almost uniformly dark brown, caudal part of abdominal tergites VII and VIII pale, legs and halteres yellowish brown. Eyes bare, ER 0.15-0.28 (0.21). Frontal tubercles (Fig. 13-a) small, $12 \mu \mathrm{m}$ high, $8 \mu \mathrm{m}$ wide at the base, and $35 \mu \mathrm{m}$ apart from each other. Antenna with 13 flagellar segments, AR 1.601.74 (1.66), AHR 0.50-0.57 (0.53). SO 912 (10.9), CL 14-18 (15.0). Antepronotum without lateral setae. DM 13-16 (15.0), DL 11-22 (14.8, highly variable in numbers), PA 4 or $5(4.8)$. Wing membrane without dark marks, but with faint cloudy areas, as in Fig. 13-b. SQ 6-10 (7.6), RR 0.17-0.27 (0.23), VR 1.19-1.39 (1.26), R/Cu 1.03$1.17(1.10)$. Terminal scale of front tibia rounded and with a small pointed process (Fig. 13-c). One terminal comb of middle and hind tibiae with a long spur, the other without spur (Fig. 13-d, e). fLR 1.96-2.08 (2.02), mLR 0.66-0.70 (0.68), hLR 0.77$0.83(0.79)$, fTR $0.34-0.36(0.35)$, fBR 3.0 3.2 (3.1), mBR 4.7-5.5 (5.2), hBR 5.8-8.3 (6.5). Pulvilli well developed.

Hypopygium in Fig. 13-f. Anal point long, narrow, and slightly constricted in the middle. Dorsal appendage (Fig. 13-g) horn-like, only slightly curved, with 1-3 inner setae at the base, and one lone lateral seta arising at distal $1 / 3$ or $1 / 4$. Ventral appendage (Fig. 13-h) finger-like, with 11 recurved setae and one long caudally directed apical seta. Gonostylus stout, widest at about basal $1 / 4$, inner margin almost straight and pointed apically, with one long apical and 4 long inner setae.

Remarks. This species is somewhat related in body coloration, in the presence of cloudy marks on wing, and in the structure of hypopygium to Polypedilum nubeculosum
(Meigen, 1818), which is widely distributed in Europe, North America and East Asia, but differs from it in that antepronotum has no lateral setae (the presence of lateral setae on antepronotum is a distinguishing character of nubeculosum), antennal ratio is less than 1.7 (2.0 or more in nubeculosum), and the numbers of setae on scutum and scutellum are larger in nubeculosum.

\section{Polypedilum tobaoctavum, sp. nov. (Fig. 14)}

A male was collected at the side of Lake Toba on Jan. 2, 1989 (holotype. No. A 200: 63). BL $3.42 \mathrm{~mm}$, WL $1.64 \mathrm{~mm}$. Ground color of scutum brown, lateral stripes dark brown, scutellum brown, postnotum black. Abdominal tergites II to VI largely yellow and each with a brown band along posterior margin, VII to hypopygium dark brown (Fig. 14-c). Front legs missing. Femora and tibiae of middle and hind legs brown, proximal $2 / 3$ of tarsi I and proximal half of tarsi II and III yellow, the rest tarsal segments brown. Wing unmarked. Antenna with 13 flagellar segments, AR 1.97, AHR 0.51. Small frontal tubercles present. ER 0.21, SO 9:9, CL 17, PN 0, DM 14, DL 20:21, PA $8: 8$, SC 22, SQ 12:12. Vein R2+3 almost fused with $\mathrm{R} 1$ along its entire length, RR 0.18. VR 1.28, R/Cu 1.11, mLR 0.64, hLR 0.81, mBR 4.5, hBR 5.5. One terminal comb of middle and hind tibiae with a long spur, the other without spur (Fig. 14-a, b).

Hypopygium in Fig. 14-d. Anal point relatively short, narrow and parallel-sided. Dorsal appendage (Fig. 14-e) horn-like and slightly hooked apically, with 3 inner setae at the base and one long lateral seta arising at about middle where lateral margin is abruptly curved. Ventral appendage (Fig. 14f) finger-like but apically tapering towards pointed tip, with one long caudally directed

Fig. 14 Polypedilum tobaoctavum, sp. nov.

a, tip of middle tibia; b, tip of hind tibia; c, abdominal tergites, showing distribution of setae (right half) and dark areas; $d$, hypopygium; e, left dorsal appendage; $f$, left ventral appendage.

Fig. 15 Polypedilum (Tripodura) tobanona, sp. nov.

a, right wing; b, tip of front tibia; $c$, tip of middle tibia; $d$, tip of hind tibia; e, hypopygium; $\mathrm{f}$, anal point, dorsal view; $\mathrm{g}$, do, ventral view; $h$, right dorsal appendage; $i$, right ventral appendage. 


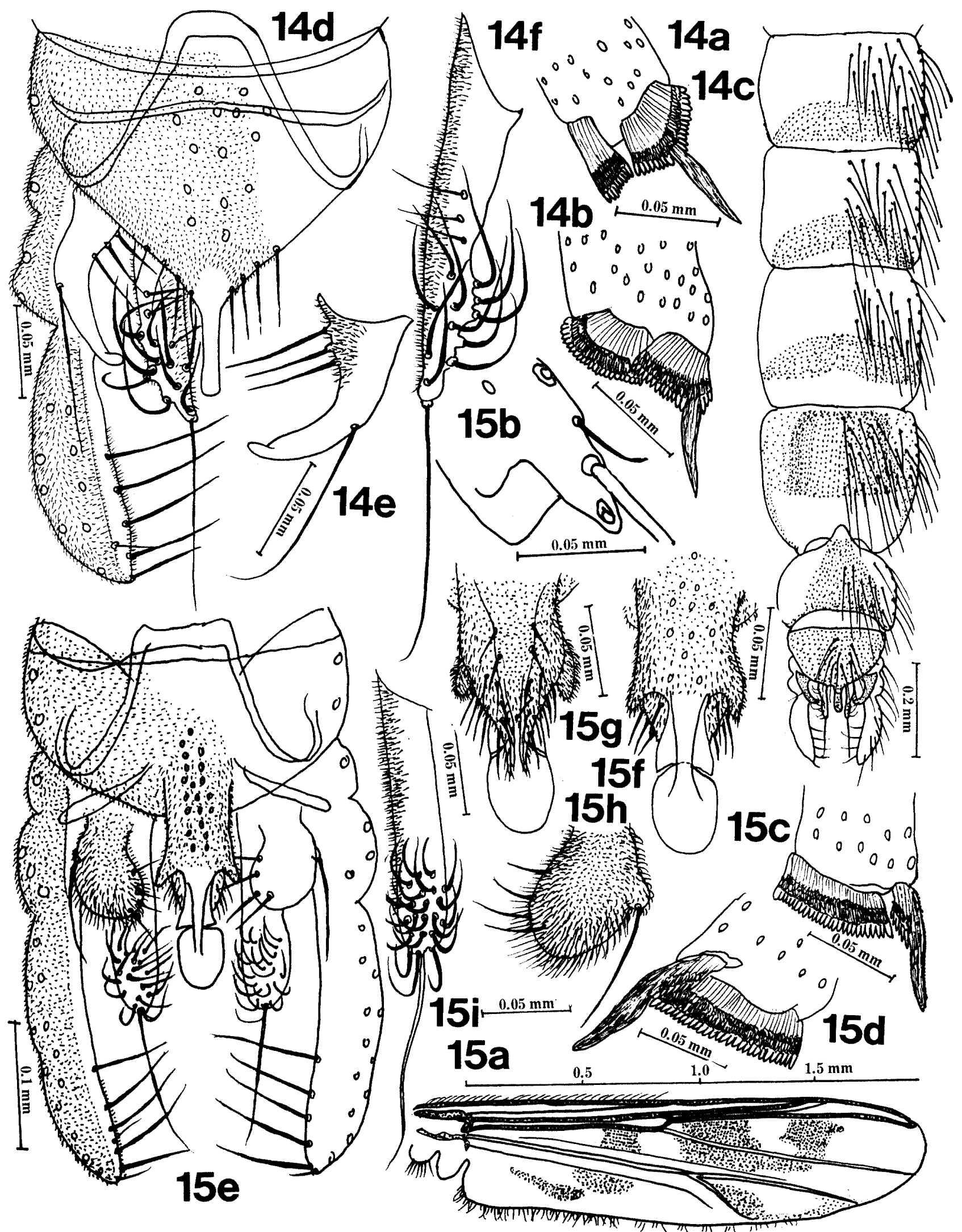

Figs. 14 and 15 
apical seta, 11 recurved setae, and two inwards directed straight setae. Gonostylus stout, widest at about distal $1 / 3$, with 4 long setae along inner margin.

Remarks. This species belongs to the nubeculosum group of genus Polypedilum, and is somewhat similar in structure to the preceding species, but can be differentiated from it in that abdominal tergites II to VI are largely pale yellow and each with a dark band along posterior margin, dorsal appendage is stouter, its base being less expanded medially and lateral seta arises at about middle, ventral appendage has a sharply pointed posterior process bearing long apical seta and bears two straight inwards directed setae, AR is higher, and scutellum and squama bear more numerous setae.

\section{Polypedilum (Tripodura) tobanona, sp. nov.}

(Fig. 15)

Seven males were collected, 3 at Samosil on Jan. 1, 1987 (No. A 199:17, 200:01, 02), 4 at Lake Toba on Jan. 1, 1989 (No. A 199:09, 38, 200:33, 62). Holotype: No. A 200:02. Paratypes: other males. BL 3.944.32 (3.12 in average of 7) $\mathrm{mm}$, WL 1.88$2.20(1.98) \mathrm{mm}$. Ground color of scutum yellow, stripes dark brown, scutellum brownish yellow, postnotum black, abdominal tergites largely dark brown and II to VII each with a narrow pale band along caudal margin, hypopygium brownish yellow; legs with dark brown and yellow rings, i.e. femora largely dark brown basally and each with a yellow ring on distal $1 / 3$ (front) or $1 / 4$ (middle and hind), front and hind tibia yellow, middle tibia largely brown and with yellow basal and apical rings, front tarsus I entirely yellow, middle and hind tarsi I as well as all other tarsal segments with a basal dark ring and distal pale ring. Wing with several rather faint dark areas, 2 in cell between $\mathrm{R} 4+5$ and $\mathrm{M}, 2$ between $\mathrm{M}$ and $\mathrm{Cu} 1$, 1 in cell between $\mathrm{Cu} 1$ and $\mathrm{Cu} 2$, and 2 between An and wing margin (Fig. 15-a). Halteres brown.

Eyes bare, ER 0.19-0.30 (0.23). Frontal tubercles absent. Antenna with 13 flagellar segments, AR 1.50-1.78 (1.61), AHR 0.48$0.52(0.50)$. Palp with 4 flagellar segments, the total length $0.504 \mathrm{~mm}$ and 0.84 times the width of head. SO 12-16 (13.6), CL 22-32 (27.8), PN 0, DM 14-26 (22.8), DL 12-21 (16.9), PA 4-8 (5.6), SG 18-24 (21.7), SQ 7-14 (10.3). Wing in Fig. 15-a. $\mathrm{R} 2+3$ is close to $\mathrm{R} 1$ but separated, RR $0.21-$ 0.25 (0.24). VR 1.12-1.23 (1.18). R/Cu 1.10-1.14 (1.12). Front tibia with a sharply pointed terminal process (Fig. 15-b). One terminal comb scale of middle and hind tibiae with a long spur, the other comb without spur (Fig. 15-c, d). fLR 1.74-2.00 (1.83), mLR 0.64-0.67 (0.65), hLR 0.75$0.78(0.76)$, fTR $0.35-0.39(0.37)$, fBR $3.5-$ 3.8 (3.6), mBR 4.4-5.4 (4.8), hBR 5.6-7.3 (6.3). Pulvilli well developed.

Hypopygium in Fig. 15-e. Ninth tergite with a long and narrow projection in the middle composed of relatively broad, apically rounded and hyaline anal point, a pair of narrow and pointed processes on posterior margin, 11-13 setae on the dorsal side (Fig. 15-f), and many short setae and microtrichiae on the ventral side (Fig. 15-g). Dorsal appendage (Fig. 15-h) elongate oval pad bearing numerous long microtrichiae and one lateral and 3 or 4 inner setae. Ventral appendage (Fig. 15-i) finger-like, bearing microtrichiae and some 20 recurved and one long caudally directed setae in the apical portion. Gonostylus widest at about middle, inner margin nearly straight, with an apical seta, and 4 long setae on inner margin.

Remarks. This species is obviously a member of the subgenus Tripodura Townes, 1945, of the genus Polypedilum Kieffer, 1913, in view of the above morphological characters, but differs from all the previously known species of this group especially in that leg segments have conspicuous dark and pale rings, and ninth tergite has a long process in the middle bearing anal point and a pair of lateral processes. A total of 18 species were recorded by Johannsen (1932) from Indonesia as members of the subgenus Polypedilum, genus Chironomus, among which C. concomitatus Johannsen, 1932, seems to be the only member of this group with the setigerous and pad-like dorsal appendage, and is similar to the present species in that anal point is broad and apically hyaline, but its tarsi are unicolorous and ninth tergite has no processes on posterior margin flanking 
anal point.

\section{Polypedilum (Tripodura) tobadecima, sp. nov.}

(Fig. 16)

A total of 10 males were collected and identified (No. A 199:11, 23, 24; 200:03, 28, 67, 86-89). Holotype: A 200:67. Paratypes: other males. BL 2.50-3.48 (3.05 in average of 10$) \mathrm{mm}$, WL $1.32-1.62$ (1.48) $\mathrm{mm}$. Scutum largely brown, scutellum yellow, postnotum dark brown, abdominal tergites largely brown and III to VIII each with a narrow pale area along caudal margin; all femora largely brown but become gradually yellow towards tip, all tibiae yellow, tarsi I to IV largely yellowish brown and each with basal and apical yellow areas, V yellow. Wing (Fig. 16-b) with faint fuscous areas, 3 between $\mathrm{R} 4+5$ and $\mathrm{M}, 3$ between $\mathrm{M}$ and $\mathrm{Cu}, 2$ between $\mathrm{Cu} 1$ and $\mathrm{Cu} 2$, and 2 behind An.

Eyes bare, ER 0.16-0.23 (0.20). Frontal tubercles absent. Antenna with 13 flagellar segments, AR 1.45-1.62 (1.50), AHR 0.470.54 (0.51). Palp with 4 flagellar segments, $32,110,116,162 \mu \mathrm{m}, 420 \mu \mathrm{m}$ in total and 1.02 times the width of head. SO 8-12 (9.9), CL 12-19 (15.7). Antepronotum (Fig. 16-a) widely separated in the middle, without lateral seta. DM 11-16 (13.5), DL 9-15 (11.8), PA 3-6 (4.7), SC 8-17 (14.1). Wing in Fig. 16-b. SQ 5-12 (7.2), RR 0.16-0.29 (0.22), VR 1.13-1.35 (1.21), R/Cu 1.06$1.15(1.10)$. Terminal process of front tibia (Fig. 16-c) broad and rounded. One terminal comb scale of middle and hind tibiae with a long spur, the other scale without spur (Fig. 16-d, e). fLR 1.85-1.97 (1.91), mLR $0.68-0.74 \quad(0.71)$, hLR $0.76-0.80$ (0.78), fTR $0.35-0.37$ (0.36), fBR 3.3-3.7 (3.5), mBR 4.8-8.0 (6.4), hBR 5.3-10.6 (8.1). Pulvilli well developed.

Hypopygium in Fig. 16-f. Ninth tergite forming acute angle at the base of anal point, and with 8-12 strong setae in the central portion, and 5 or 6 short setae on both sides of the base of anal point. Anal point relatively short, narrow and parallel-sided. Dorsal appendage (Fig. 16-g) pad-like and with rounded posterior margin, bearing 3 or 4 long setae on posterior margin, and covered thickly with microtrichiae. Ventral appendage (Fig. 16-h) finger-like, with 12 recurved setae on distal half, and one long caudally directed apical seta. Gonostylus long, slender, and bearing two rows of long setae on inner margin.

Remarks. The above morphological characters, especially the structure of dorsal appendage being pad-like, pubescent and bearing long marginal setae, indicate that the present species belongs to the subgenus Tripodura Townes, 1945, of genus Polypedilum, and is similar in morphological characters to Polypedilum (Polypedilum) concomitatus (Johannsen, 1932) of Tokunaga (1964) described with specimens collected on Caroline Islands, Micronesia. However, this Tokunaga's species seems to be different from the type specimens of Johannsen (1932, p. 517, Fig. 5), because in the latter anal point is broad and apically hyaline such as in the previous species.

\section{Polypedilum (Tripodura) tobaundecima, sp. nov.}

(Fig. 17)

Six males were collected and identified, 2 at Samosil on Jan. 1, 1987 (No. A 199:16, 200:04), 4 at the side of Lake Toba on Dec. 30, 1987 (No. A 200:29) and Jan. 2, 1989 (No. A 199:39, 200:60, 61). Holotype: No. A 200:61. Paratypes: other males. BL 2.28 2.46 (2.36 in average of 6 ) $\mathrm{mm}$, WL $1.11-$ $1.20(1.15) \mathrm{mm}$. Ground color of scutum yellow, stripes brown, scutellum yellow, postnotum dark brown, abdominal tergites I-VI brown, VII and IX dark brown; Wing membrane with 3 rather conspicuous dark marks, one between $\mathrm{R} 4+5$ and $\mathrm{M}$, one between $\mathrm{Cu} 1$ and $\mathrm{Cu} 2$, another between An and wing margin (Fig. 17-a). Halteres yellow. Coxae and trochanters of all legs dark brown: in the front leg, proximal $2 / 3$ and tip of femur dark brown with yellow ring between them, tibia yellowish brown, tarsi brown; in the middle leg, distal half of femur and proximal half of tibia yellow, tip of tarsus I, base and tip of tarsus II yellow, the rest leg parts brown or dark brown; in the hind leg, distal half of femur, entire tibia, base and tip of tarsi I and II yellow, the rest leg parts brown.

Eyes bare, ER 0.10-0.28 (0.16). Frontal 


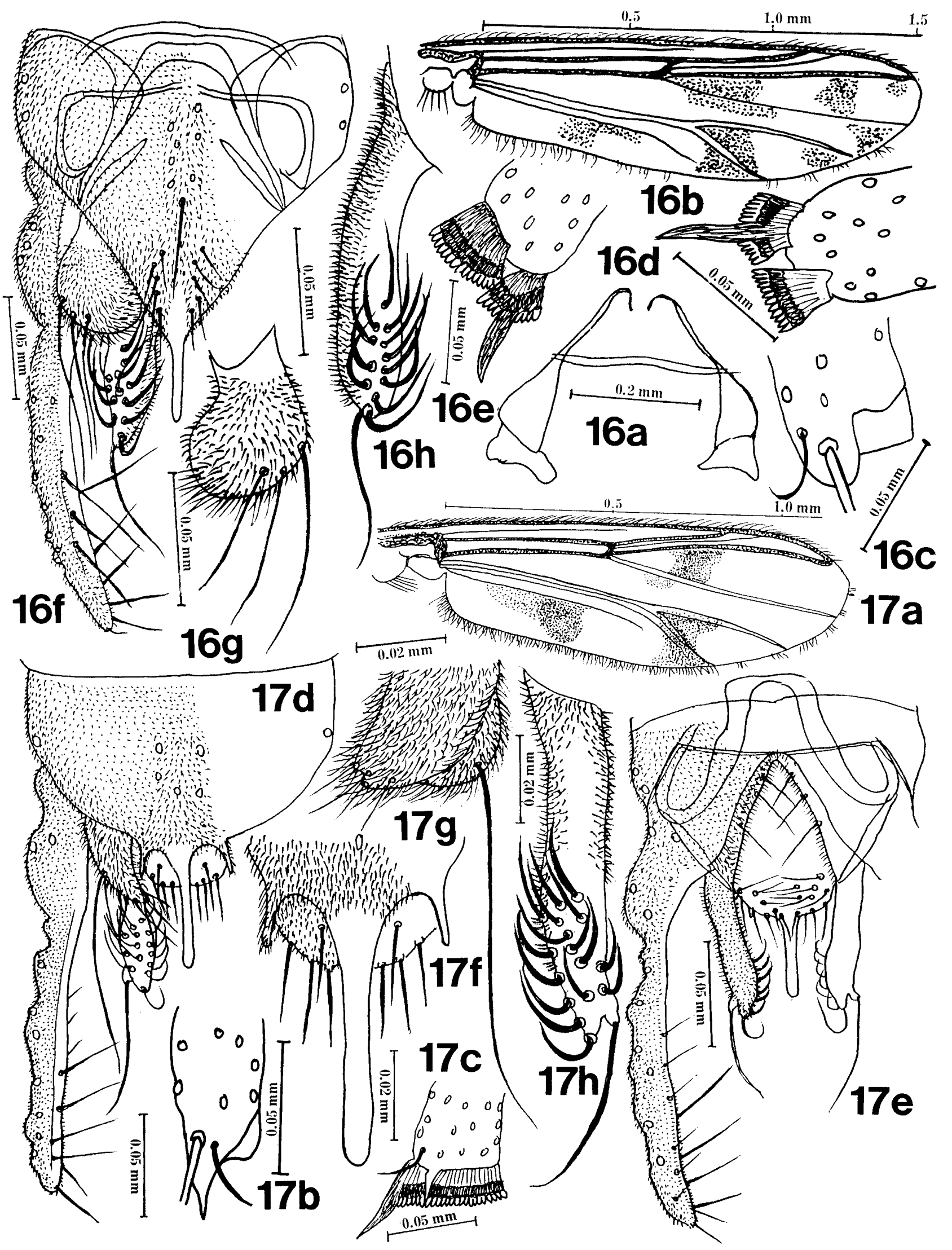

Figs. 16 and 17 
tubercles absent. Antenna with 13 flagellar segments, AR 0.60-0.73 (0.65), AHR 0.400.47 (0.42), both much smaller than the other Tripodura species. Palp with 4 flagellar segments $(24,62,88,110 \mu \mathrm{m})$, the total length being $78 \%$ of the width of head. SO 8 or 9 (8.3), CL 14-17 (15.0). Antepronotum without lateral seta. DM 14-16 (15.0), DL 11-14 (most frequently 12, mean 12.3), PA 4 (excepting a single specimen with 3 on one side), SC 6-11 (8.8). Wing in Fig. 17-a. SQ 4-6 (5.1). R2+3 separated from R1， RR 0.11-0.29 (0.22), VR 1.32-1.39 (1.36)，R/Cu 1.05-1.14 (1.08). Terminal scale of front tibia broad and apically pointed (Fig. 17-b). One terminal comb scale of middle and hind tibiae with a long spur, the other scale without spur (Fig. 17-c). fLR 2.00-2.07 (2.04), mLR 0.61-0.64 (0.62), hLR 0.75-0.79 (0.77), fTR 0.38-0.40 (0.39), fBR 3.8-4.3 (4.1), mBR 4.5-5.3 (4.7), hBR 5.4-8.4 (6.7).

Hypopygium in Fig. 17-d, e. Anal point (Fig. 17-f) long, narrow, parallel-sided and with rounded apex. Ninth tergite with a pair of narrow and pointed process flanking anal point (Fig. 17-f). Dorsal appendage (Fig. 17-g) broad, pad-like and with one long seta on posterior margin. Ventral appendage (Fig. 17-h) with 14 recurved setae and one long caudally directed apical seta. Gonostylus long, narrow and apically pointed, with two rows of long setae along inner margin.

Remarks. This species is again a member of subgenus Tripodura of genus Polypedilum, and also unique in the peculiar dark and pale rings on leg segments, in the presence of narrow and pointed processes flanking anal point, and in that $\mathrm{AR}$ is less than 0.7 .

\section{Stenochironomus tobaduodecimus, sp. nov. (Fig. 18)}

Two males were collected at the side of Lake Toba on Jan. 2, 1989 (holotype: No. A
200:55; paratype: No. A 200:56). BL 4.22, $4.32 \mathrm{~mm}$, WL $1.91,1.92 \mathrm{~mm}$. Scutum and scutellum (Fig. 18-b) largely pale yellow, only posterior $1 / 3$ of median stripes faintly brown and posterior $2 / 3$ of lateral stripes dark brown; postnotum dark brown; posterior $2 / 3$ of abdominal tergite II, posterior half of III, and posterior $1 / 3$ of IV dark brown, other abdominal parts entirely pale yellow, hypopygium yellowish brown; all coxae and trochanters pale yellow, front femur largely yellow and slightly brownish apically, front tibia brown, front tarsi yellowish brown; middle and hind leg segments entirely yellow; wing unmarked.

Eyes bare, ER 0.28, 0.29. Frontal tubercles absent. Antenna with 13 flagellar segments, AR 1.65, 1.67, AHR 0.53, 0.56. SO 15:16, 16:16, CL 14, 18. Antepronotum (Fig. 18-a) reduced towards middle and not united, without lateral setae. DM 18, 18, DL 11:13, $12: 13$, PA $5: 6,6: 6$, SG 17,18 in two rows, SQ 12:12, 8:8. Wing membrane granular, and without dark marks. $\mathrm{R} 2+3$ fused with R1，RR 0.06, 0.09. VR 1.15, 1.15， R/Cu $1.11,1.13$. Terminal scale of front tibia (Fig. 18-c) broad and with pointed apex. Terminal comb scales of middle and hind tibiae (Fig. 18-d, e) contiguous and both with a spur. fLR 1.26, 1.27, mLR $0.73,0.76$, hLR 0.81, 0.81, fTR 0.23, 0.24, fBR 4.2, 4.5, mBR 6.2, 6.3, hBR 8.0, 9.0. Pulvilli, empodium and claws well developed (Fig. 18-f).

Hypopygium in Fig. 18-g, h. Anal point long, slender and parallel-sided. Ninth tergite with numerous long setae in the central region and short but strong setae on both sides of the base of anal point. Dorsal appendage (Fig. 18-i) short and thumb-like, with 4 or 5 setae on posterior margin but without microtrichiae. Ventral appendage (Fig. 18-j) extremely long, smoothly curved, with a strong apical spur (18 $\mu \mathrm{m}$ long and $5 \mu \mathrm{m}$ wide) and 3 subapical setae on inner margin. Gonostylus also very long and slender, smoothly curved and nearly parallel-

Fig. 16 Polypedilum (Tripodura) tobadecima, sp. nov.

a, antepronotum; b, wing; c, tip of front tibia; $d$, tip of middle tibia; e, tip of hind tibia;

$\mathrm{f}$, hypopygium; $\mathrm{g}$, right dorsal appendage; $\mathrm{h}$, right ventral appendage.

Fig. 17 Polypedilum (Tripodura) tobaundecima, sp. nov.

$a$, wing; $b$, tip of front tibia; $c$, tip of hind tibia; $d$, hypopygium, dorsal view; e, hypopygium, ventral view; $f$, anal point; $g$, right dorsal appendage; $h$, ventral appendage. 
Jpn. J. Sanit. Zool.

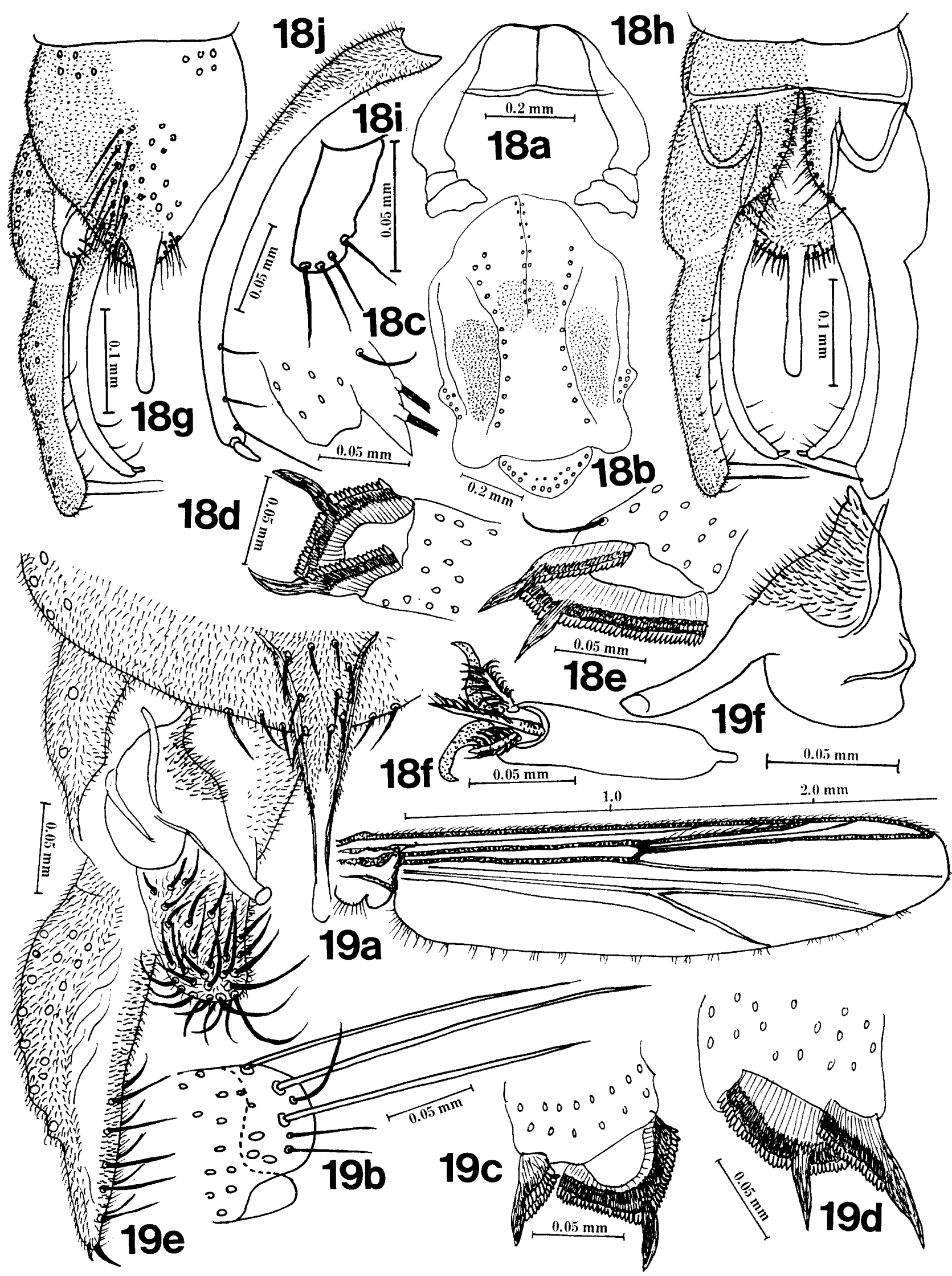

Figs. 18 and 19 
sided, with rounded apex.

Remarks. This species is a typical member of genus Stenochironomus, since antenna with 13 flagellar segments, antepronotum is reduced towards middle and not united, dorsal appendage is small and thumb-like, ventral appendage is extremely long and with a distinct apical spine. A review of this genus was made by Yamamoto (1981), who recorded two new species from Japan. All the previously known species of this genus have dark spots on wing, except $S$. membranifer Yamamoto, 1981, but it differs from the present species in that scutum with only two dark areas, and abdominal tergites VI to hypopygium are dark brown while $\mathrm{I}$ to $\mathrm{V}$ are pale yellow.

\section{Sumatendipes, gen. nov.}

A genus within the Polypedilum complex of tribe Chironomini. Male antenna with 13 flagellar segments, frontal tubercles absent, antepronotum with lateral setae, dorsomedian setae absent, wing without macrotrichiae but granular, R $2+3$ well separated from both $\mathrm{R} 1$ and $\mathrm{R} 4+5$, fCu only slightly beyond $\mathrm{r}-\mathrm{m}$. Terminal comb scales of middle and hind tibiae separated and both with a short spur; pulvilli well developed. Ninth tergite is very short and has no long setae in the middle such as seen in most other Chironomini species. Anal point very long and with several setae on dorsal side. Dorsal appendage composed of a basal globular part bearing numerous microtrichiae but without long setae, and a bare distal blade. Ventral appendage thumb-like, with many recurved setae but without caudally directed long apical setae.

Remarks. The above combination of morphological characters indicate that it belongs to the Tribe Chironomini of subgenus Chironominae, and is somewhat related to members of the genus Einfeldia Kieffer, 1924, in that dorsal appendage is composed of a broad base and bare distal blade, but differs from it in that male antenna has 13 flagellar segments (11 in Einfeldia), antepronotum has lateral setae (bare in Einfeldia), anal point bears dorsal setae (without setae in Einfeldia), and dorsal appendage has no long setae. It is also similar to members of the genus Endochironomus in that male antenna has 13 flagellar segments, terminal combs of middle and hind tibiae with two short spurs, and ventral appendage has no long terminal seta such as seen in members of the genus Polypedilum, but again differs from them in that ventral appendage has no long apical seta, dorsal appendage is strongly expanded basally, anal point has dorsal setae but ninth tergite has no long setae in the middle, and antepronotum has lateral setae.

Type species. Sumatendipes tobaterdecimus, sp. nov., monotypic.

\section{Sumatendipes tobaterdecimus, sp. nov. (Fig. 19)}

A male was collected at the side of Asahan Dam, Sumatra, on Jan. 3, 1989 (holotype: No. A 200:77). BL $6.50 \mathrm{~mm}$, WL $2.77 \mathrm{~mm}$. Ground color of scutum brown, scutal stripes dark brown, scutellum brown, postnotum black, abdominal tergites largely black but lateral portions of tergites $\mathrm{V}$ to VIII are slightly paler in gum-chloral mounted specimen; leg segments also black, excepting trochanter and basal as well as distal portions of femora which are yellowish brown. Eyes bare, ER 0.11. Frontal tubercles absent. Antenna with 13 flagellar segments, AR 2.56, AHR 0.55, SO 20:21, CL 16, PN 8:8, DM 0 , DL 8:8, PA 3:3, SC 6 . Wing in Fig. 19-a. Squama with 8 fringe hairs. Wing membrane bare and without dark spots, slightly bluish and very finely granular. $\mathrm{R} 2+3$ separated from $\mathrm{Rl}$ and $\mathrm{R} 4+5$, ending closer to tip of $\mathrm{R} 1$ than to tip of $\mathrm{R} 4+5, \mathrm{RR} 0.32$.

Fig. 18 Stenochironomus tobaduodecimus, sp. nov.

a, antepronotum; b, scutum and scutellum, showing bases of setae, and dark areas; $c$, tip of front tibia; d, tip of middle tibia; e, tip of hind tibia; $f$, hind tarsus $\mathrm{V}$; $\mathrm{g}$, hypopygium, dorsal view; $h$, do., ventral view; $i$, left dorsal appendage; $j$, left ventral appendage.

Fig. 19 Sumatendipes tobaterdecimus, gen. et sp. nov.

a, wing; b, tip of front tibia; $c$, tip of middle tibia; d, tip of hind tibia; e, hypopygium;

f, right dorsal appendage. 
fCu only slightly beyond $\mathrm{r}-\mathrm{m}, \mathrm{VR}$ 1.08. Tip of $\mathrm{R} 4+5$ beyond tip of $\mathrm{Cu} 1, \mathrm{R} / \mathrm{Cu}$ 1.13. Anal vein extending much beyond fCu. Tip of front tibia (Fig. 19-b) with a rounded terminal scale bearing 3 subapical setae. Terminal combs of middle and hind tibiae (Fig. 19-c, d) narrowly separated and both with a short spur. Front tarsi broken off. mLR 0.49, hLR 0.74, mBR 2.0, hBR 2.6. Pulvilli well developed.

Hypopygium in Fig. 19-e. Anal point very long, somewhat triangular, widest at base and tapering towards apex, but with rounded apex, bearing 9 short setae on dorsal side, and numerous microtrichiae on basal $3 / 4$ of both dorsal and ventral side. Ninth tergite with one short seta on both sides of anal point but without long setae in the central portion. Dorsal appendage (Fig. 19-f) composed of a large globular base covered thickly with microtrichiae on the inner and basal portion but without long seta, and a bare horn-like and apically hooked distal blade. Ventral appendage short, stout and thumblike, with 30 stout and recurved setae on dorsal side and 3 short caudally directed setae on ventral side of distal portion, but without long apical seta such as seen in species of Polypedilum and Endochironomus. Gonostylus widest at about proximal 1/3 and tapering towards pointed apex, with a short apical seta, and two rows of each 5 setae on inner margin.

Remarks. This species can be separated from other members of the Tribe Chironomini by the peculiar morphological characters stated in the definition of this new genus. The trivial name is abbreviated from the latin word "tertius decimus" (thirteenth).

\section{Cladotanytarsus tobaquardeci- mus, sp. nov. (Fig. 20)}

Six males were collected at the side of Lake Toba on Jan. 2, 1989. Holotype: No. A
200:70. Paratypes: No. A 200:68, 69; 199: 31-33. BL 2.00-2.32 (2.17 in average of 6) $\mathrm{mm}$, WL 1.06-1.19 (1.11) $\mathrm{mm}$. Ground color of scutum pale, stripes brown, scutellum pale, postnotum brown, abdominal tergites pale; wing unmarked, femora and tibiae brownish yellow, tarsi yellow. Head in Fig. 20-a. Eyes bare, reniform and without dorsomedial projection (a characteristic of this genus), ER 1.00-1.05 (1.03). Frontal tubercles conical, $5 \mu \mathrm{m}$ wide and $5 \mu \mathrm{m}$ high, $20 \mu \mathrm{m}$ apart from each other. Antenna with 13 flagellar segments, AR 0.67-0.78 (0.73), AHR $0.47-0.54(0.50)$. SO 6,7 or 8 on each side, 5.8 in average. CL 8-10 (9.2). Antepronotum without lateral setae. DM 6-9 (8.0), DL 6 or 7 (6.2), PA 1 or 2 (1.1), SC 4 in all. Wing in Fig. 20-b. Squama bare, macrotrichiae are distributed sparsely on distal half only. RR $0.38-0.55 \quad(0.45)$, VR 1.22-1.33 (1.27), R/Cu 1.04-1.10 (1.07). Tip of front tibia (Fig. 20-c) with a long, narrow and pointed terminal scale. Terminal combs of middle and hind tibiae (Fig. 20-d, e) separated, both with a long spur. fLR 2.32-2.58 (2.44), mLR 0.59-0.65 (0.62), hLR 0.64-0.69 (0.68). Pulvilli absent.

Hypopygium in Fig. 20-f. Bands of ninth tergite widely separated in the middle. Anal point narrow, widest at base and tapering towards pointed apex. Ninth tergite with 3-5 short setae at the base, and 3 or 4 short setae on both sides of anal point. Dorsal appendage (Fig. 20-g, h) roughly triangular and apically pointed but with slightly concave inner margin, with 3 dorsal setae and one basal seta arising on an elevated base. Digitus (Fig. 20-h) long, slender and almost parallel-sided. Ventral appendage (Fig. 20-i) stout, short and thumb-like, with 7 recurved setae in distal part of dorsal side. Median appendage (Fig. 20-i) with numerous long and branched setae. Gonostylus widest at about middle and tapering towards pointed apex.

Fig. 20 Cladotanytarsus tobaquardecimus, sp. nov.

$\mathrm{a}$, head; $\mathrm{b}$, right wing; $\mathrm{c}$, tip of front tibia; $\mathrm{d}$, tip of middle tibia; e, tip of hind tibia;

$\mathrm{f}$, hypopygium; g, left dorsal appendage and digitus, dorsal view; h, do., ventral view;

$i$, ventral and median appendages.

Fig. 21 Cladotanytarsus tobaquindecimus, sp. nov.

$\mathrm{a}$, head; b, antepronotum; $\mathrm{c}$, hypopygium; $d$, left dorsal appendage and digitus, dorsal view;

$\mathrm{e}$, do., ventral view; $\mathrm{f}$, ventral and median appendages. 


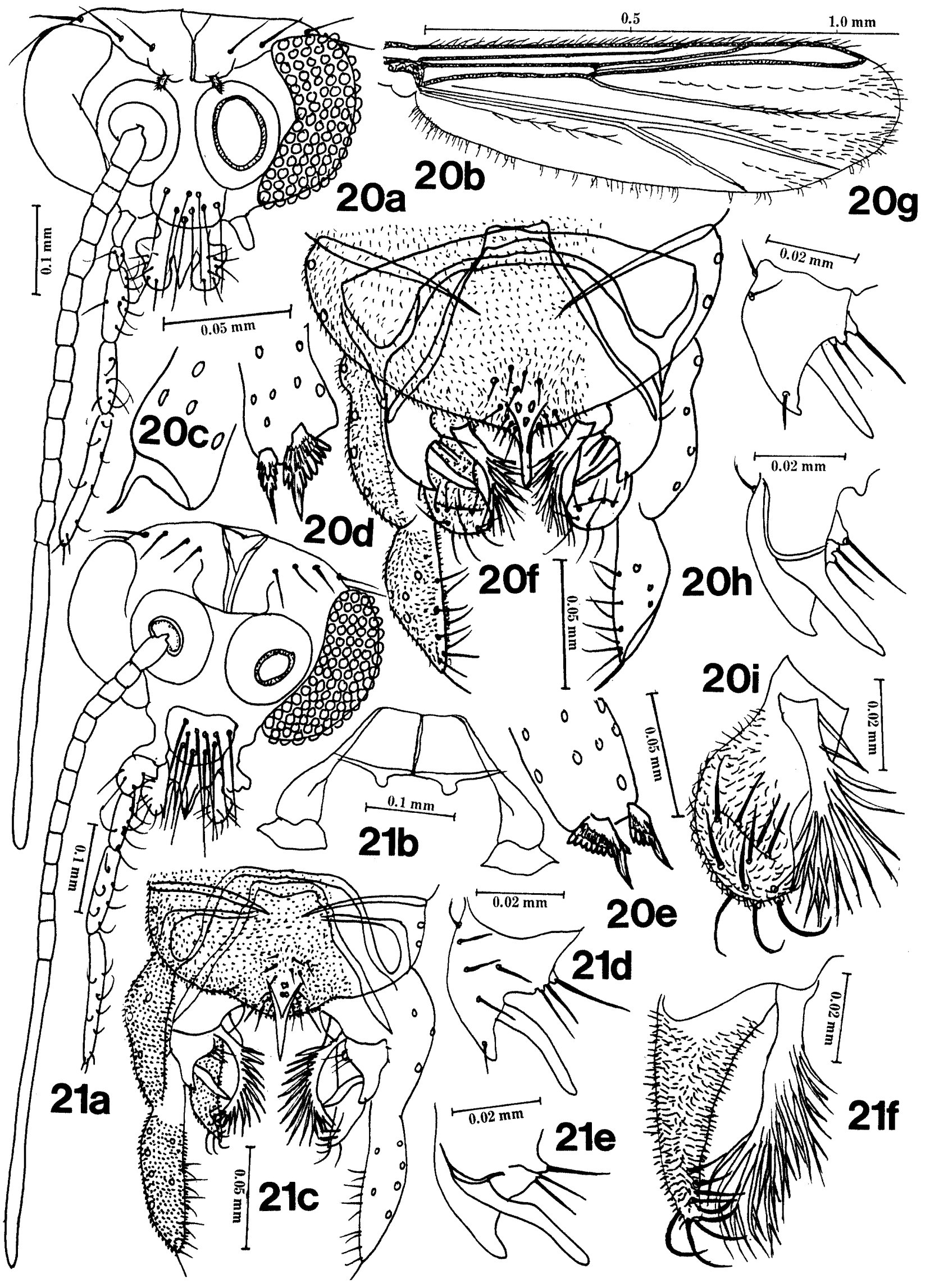

Figs. 20 and 21 
Remarks. This species is a typical member of genus Cladotanytarsus Kieffer, 1922, since eyes are reniform and widely separated from each other, wing with macrotrichiae rather sparsely in distal half only, tibial combs are separated and both with a long spur, and median appendage of hypopygium has numerous long and branched setae. Among the previously known species of this genus, it is most closely related to $C$. vanderwulpi (Edwards, 1929) in that it is a small midge with wing length less than $1.5 \mathrm{~mm}, \mathrm{AR}$ is less than 1.0, and in the structure of dorsal, ventral and median appendages, but the present species differs essentially from vanderwulpi in that anal point is very narrow, parallel-sided and apically rounded (it is stout, roughly triangular and apically pointed in vanderwulpi). The trivial name is abbreviated from "quartus decimus" (fourteenth).

\section{Cladotanytarsus tobaquindeci- mus, sp. nov. (Fig. 21)}

Two males were collected at Samosil on Jan. 1, 1987. Holotype: No. A 199:18. Paratype: No. A 200:07. BL 2.22, $2.14 \mathrm{~mm}$, WL $1.09,1.12 \mathrm{~mm}$. Ground color of scutum pale, stripes brownish yellow, scutellum pale, postnotum brown, halteres pale yellow, leg segments yellow, abdomen almost uniformly yellow. Head in Fig. 21-a. Eyes reniform, without dorsomedial projection, ER 1.17, 1.26. Frontal tubercles absent. Antenna with 13 flagellar segments, AR 0.79, 0.87 (larger than in the preceding species), AHR 0.47, 0.54 . SO 6:6, 8:8, CL 8, 11. Antepronotum widely separated in the middle, without lateral setae (Fig. 21-b). DM 6, 10, DL 5:6, $7: 7$, PA 1:1, SC 4, 4, SQ 0:0. Wing with macrotrichiae sparsely on distal half. RR $0.53,0.56$, VR 1.29, 1.30, R/Cu 1.00, 1.04 . Terminal structure of tibiae as in other Cladotanytarsus and Tanytarsus species. fLR 2.55, 2.57, mLR 0.57, 0.60, hLR 0.68, 0.69, fTR $0.40,0.42$, fBR 3.4 .

Hypopygium in Fig. 2-c. Bands of ninth tergite separated in the middle. Anal point very narrowly triangular, tapering towards pointed apex, with 2 spine clusters between strong lateral ridges. Dorsal appendage (Fig. 21-d, e) broad and wide, roughly triangular and with concave inner margin. Digitus (Fig. 21-e) long, slender and curved. Ventral appendage (Fig. 21-f) long, finger-like and tapering towards apex, with 8 recurved setae in the apical portion. Median appendage (Fig. 21-f) with numerous long and branched setae.

Remarks. This species is also a typical member of genus Cladotanytarsus Kieffer, 1922 , and is most closely related to the preceding species in body coloration, in wing length, AR and other measurement data, but differs essentially from it in that frontal tubercles are absent, ventral appendage is much narrower and tapering towards apex (stout and swollen apically in the preceding species), inner margin of dorsal appendage is more conspicuously concave, digitus is longer and curved, and anal point is narrower and tapering to sharply pointed apex (narrow but parallel-sided and apically rounded in the preceding species). The trivial name is abbreviated from "quintus decimus" (fifteenth).

\section{Cladotanytarsus tobasexdecimus, sp. nov. (Fig. 22)}

A male was collected at the side of Lake Toba on Jan. 1, 1987 (holotype: No. A 200: 21). BL $2.44 \mathrm{~mm}$, WL $1.30 \mathrm{~mm}$. Ground color of scutum pale, median and lateral stripes dark brown, scutellum pale, postnotum dark brown; abdominal tergites largely pale but II to VII each with narrow dark bands along oral and caudal margins (Fig. 22-a); front leg segments all dark brown, middle and hind femora yellow for basal half and brownish for distal half, other segments yellow. Eyes reniform and without dorsomedial projection, ER 1.02. Frontal tubercles absent. Antenna with 13 flagellar segments, AR 1.06, AHR 0.48. Palp with 4 flagellar segments, $365 \mu \mathrm{m}$ long in total and 0.95 times as long as the width of head. SO 10:10, CL 12 . Antepronotum widely separated in the middle, without lateral setae. DM 4, DL 6:6, PA $1: 1$, SC 6, SQ 0:0. Wing with macrotrichiae rather sparsely in distal portion only. RR 0.47, VR 1.29, R/Cu 1.07. Terminal structure of tibiae as in genus Tanytarsus, i.e. terminal process of front tibia narrow and sharply pointed, terminal comb scales 
of middle and hind tibiae separated and both with a long spur. fLR 2.46, mLR 0.57 , hLR 0.64, fTR 0.35. Pulvilli absent.

Hypopygium in Fig. 22-b. Bands of ninth tergite separated in the middle. Anal point rather stout, widest at base and tapering towards pointed apex, with a subapical neck, and bearing as many as 32 spine clusters irregularly distributed between lateral ridges. Dorsal appendage (Fig. 22-c) roughly semicircular, outer margin smoothly convex and inner margin concave, with 7 setae on dorsal side, and a long ventral seta arising on a large tubercle at the base of digitus. Digitus (Fig. 22-c) long and curved. Ventral appendage (Fig. 22-d) finger-like, not expanded apically, with 10 recurved setae in the apical portion. Median appendage (Fig. 22-d) with numerous long and branched setae. Gonostylus widest at about basal $1 / 3$, outer margin smoothly convex, inner margin almost straight.

Remarks. This is again a member of genus Cladotanytarsus, since eyes are reniform and without dorsomedial projection, wing with macrotrichiae towards tip, and median appendage with numerous long and branched setae. This species differs from the preceding two Cladotanytarsus species in that abdominal tergites have dark transversal bands, and anal point is stout and has numerous irregularly distributed spine clusters. Among the previously known species of this genus, it is most closely related to $C$. vanderwulpi (Edwards, 1929), which is widely distributed in Europe and Japan, especially in body size being very small, in the shape of anal point and dorsal appendages, but differs essentially in that spine clusters of anal point is numerous, and abdominal tergites have peculiar transversal bands.

\section{Rheotanytarsus tobaseptideci- mus, sp. nov. (Fig. 23)}

Two males were collected at the side of Lake Toba, one on Jan. 1, 1987 (Holotype: No. A 200:15), another on Dec. 30, 1987 (Paratype: No. A 200:34). BL 2.26, 2.00 $\mathrm{mm}$, WL 1.33, $1.18 \mathrm{~mm}$. Ground color of scutum yellow, stripes brown, scutellum yellow, postnotum dark brown, abdominal tergites yellow, front leg segments brown, mid- dle and hind leg segments largely yellow but distal $1 / 5$ of femora brown. Eyes bare, each with dorsomedial projection, ER 0.28, 0.34 (these values are much smaller than in those of Cladotanytarsus, which are around 1.0). Frontal tubercles absent. Antenna with 13 flagellar segments, AR 0.66, 0.68, AHR 0.37, 0.41 . SO $8: 8,10: 10$, CL 15, 15. Antepronotum (Fig. 23-a) widely separated, and without lateral setae. DM 18, 20 (very many), DL $8: 8,8: 8$, PA $1: 1$, SC 4 , 6, SQ 0 . Wing with macrotrichiae on almost entire length. RR 0.48, 0.52, VR 1.38, 1.44, R/Cu 1.10, 1.11. Terminal structure of tibiae as in other species of this genus and Tanytarsus, i.e. terminal process of front tibia narrow and pointed, terminal combs of middle and hind tibiae separated and both with a long spur. fLR 2.00, 2.11, mLR 0.60, 0.61, hLR 0.66, 0.67, fTR 0.30, 0.30, fBR 2.7, 3.0, mBR 3.6, 3.8, hBR 4.0, 4.2. Pulvilli absent.

Hypopygium in Fig. 23-b. Bands of ninth tergite ( $B$ in Fig. 23-b) united in the middle. Anal point roughly long and narrow bottleshaped, with strong lateral ridges, slightly constricted in the middle, and without spine clusters. Dorsal appendage (DA in Fig. 23-c) thumb-shaped, with 8 dorsal setae and a basal seta. Digitus absent. Ventral appendage (VA in Fig. 23-c) finger-like and swollen apically, with 20 recurved setae on dorsal side and one relatively long caudally directed seta on ventral side near apex. Median appendage (MA in Fig. 23-c) with simple setae reaching to about middle of ventral appendage. Gonostylus widest at about basal $1 / 3$, and slightly constricted at about distal $1 / 3$.

Remarks. This species is considered as to belong to the genus Rheotanytarsus of the tribe Tanytarsini, subfamily Chironominae, because it is closely related to members of genus Tanytarsus but anal point is narrow and with strong lateral ridges but without spine clusters, digitus is absent, and gonostylus is constricted in the distal portion. This species is somewhat related to $R$. muscicola Kieffer of Europe in that body is largely brown and with dark brown scutal stripes, anal point is long and narrow, and setae on median appendage is relatively short, but differs from it in the shape of dorsal appendage, which is about 3 times as long as 


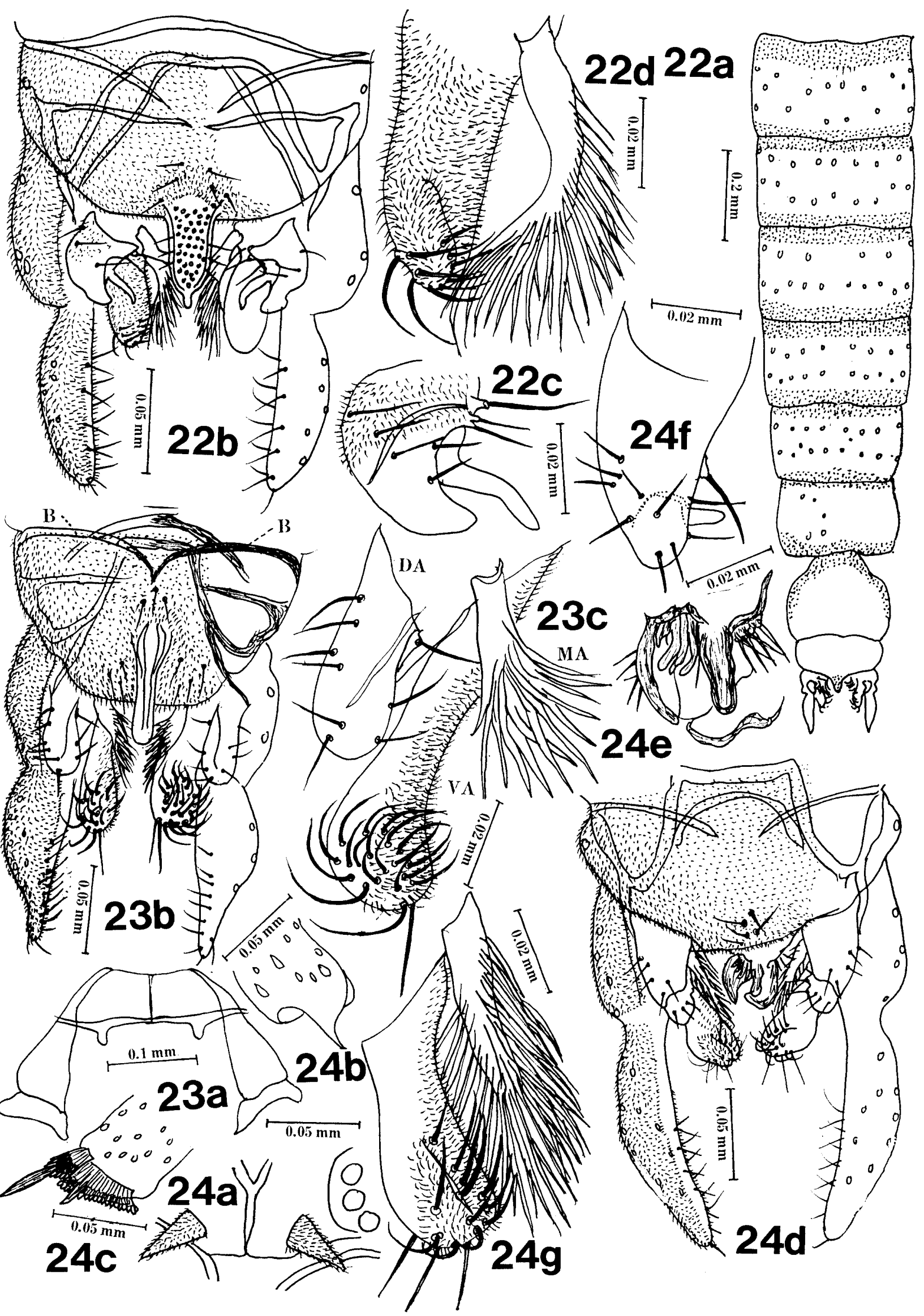

Figs. 22-24 
wide (in the previously known species of this genus, it is less than twice as long as wide). Among the species of this genus known from Japan, the present species is most closely related to $T$. parvicrinis (Tokunaga, 1938) in body coloration and structure of hypopygium, but again differs from it in the shape of dorsal appendage being much longer. The trivial name is abbreviated from "septimus decimus" (seventeenth).

\section{Tanytarsus tobaoctadecimus, sp. nov. (Fig. 24)}

A male was collected at the side of Lake Toba on Jan. 1, 1978 (holotype: No. A 199: 10). BL $2.70 \mathrm{~mm}$, WL $1.34 \mathrm{~mm}$. Ground color of scutum pale, stripes brownish yellow, scutellum pale, postnotum brownish yellow, abdomen yellow, hypopygium brownish yellow, front tarsi brownish yellow, other leg segments yellow. Eyes bare, each with a conspicuous dorsomedial projection, ER 0.29. Frontal tubercles (Fig. 24-a) prominent, roughly conical, $30 \mu \mathrm{m}$ high, $20 \mu \mathrm{m}$ wide at the base, and $45 \mu \mathrm{m}$ apart from each other. Antenna with 13 flagellar segments, AR 0.73, AHR 0.52. SO 8:8, CL 13. Antepronotum widely apart from each other, without lateral setae. DM 7, DL 8:9, PA $1: 1$, SG 6, SQ $0: 0$. Wing with macrotrichiae on almost entire surface. RR 0.47 , VR $1.29, \mathrm{R} / \mathrm{Cu}$ 1.07. Terminal process of front tibia (Fig. 24-b) long, narrow and pointed. Terminal comb scales of middle and hind tibiae are separated, one with a long spur and the other with a short spur (Fig. 24-c). fLR 3.24 (unusually high), mLR 0.64, hLR 0.81, fTR 0.47. Pulvilli absent.

Hypopygium in Fig. 24-d. Bands of ninth tergite separated in the middle. Anal point (Fig. 24-e) highly complicated in structure and chitinized, composed of a central pro- cess, a pair of lateral capsule, and with strong spines at base. Dorsal appendage (Fig. 24-f) long and thumb-like, $50 \mu \mathrm{m}$ long and $30 \mu \mathrm{m}$ wide at the base, with 10 short setae on dorsal side and one long seta arising from a tubercle at the base. Digitus small, slightly extending beyond inner margin of dorsal appendage. Ventral appendage (Fig. 24-g) finger-like, with 10 recurved setae on dorsal side and 3 caudally directed setae on ventral side of distal portion. Median appendage (Fig. 24-g) with numerous long and simple setae, the distal ones reach to almost the tip of ventral appendage. Gonostylus widest at about middle, outer margin smoothly convex.

Remarks. This species is considered as to belong to Tanytarsus van der Wulp, but is quite unusual as a member of this genus in that anal point is highly complicated in structure and quite different from that of the previously known species of this genus, and dorsal appendage is very long and thumblike. The leg ratios of all legs are unusually high. The trivial name is modified from "duodevicesimus" (eighteenth).

\section{Tanytarsus euformosanus, sp. nov. (Fig. 25)}

A total of 12 males were examined after mounted on slides, 7 collected on Jan. 1, 1987, at the side of Lake Toba (No. A 199: $13,200: 13,17,18,20,35,71)$, and 5 on Jan. 3,1989 , at the side of Asahan Dam (No. A 199:21, 22; 200:90-92). Holotype: No. A $200: 13$. Paratypes: 11 other males. BL 2.543.44 (3.01 in average of 11$) \mathrm{mm}$, WL 1.30 1.80 (1.51 in average of 12$) \mathrm{mm}$. Ground color of scutum pale, median stripes yellowish brown, lateral stripes largely brown and with a dark brown area in the lateral and posterior region, scutellum pale, postnotum dark brown, leg segments largely yellowish

Fig. 22 Cladotanytarsus tobasexdecimus, sp. nov.

a, abdominal tergites, showing distribution of setae and dark areas; b, hypopygium; c, left dorsal appendage and digitus; $d$, left ventral and median appendages.

Fig. 23 Rheotanytarsus tobaseptidecimus, sp. nov.

a, antepronotum; b, hypopygium; c, dorsal (DA), ventral (VA) and median (MA) appendages.

Fig. 24 Tanytarsus tobaoctadecimus, sp. nov.

a, frontal tubercles; b, tip of front tibia; c, tip of hind tibia; d, hypopygium; e, anal point and attached processes; $f$, dorsal appendage; $g$, median and ventral appendages. 
brown, apical portion of all tibiae slightly darker; abdominal tergites II to VII each with an anterior pale yellow area and posterior dark brown area, the border line being roughly W-shaped (Fig. 25-f).

Head in Fig. 25-a. Frontal tubercles (Fig. 25-b) prominent, long and conical, $52 \mu \mathrm{m}$ long, $22 \mu \mathrm{m}$ wide at the base, and $70 \mu \mathrm{m}$ apart from each other. Eyes bare, each with a prominent dorsomedial projection, ER 0.37-0.72 (0.53 in average of 12). Antenna with 13 flagellar segments, $\mathrm{AR}$ 1.09-1.47 (1.20), AHR 0.48-0.56 (0.52). SO 8-13 (10.3), CL 14-23 (15.9). Antepronotum (Fig. 25-c) widely separated, without lateral seta. DM 8-19 (12.8), DL 6-19 (7.7), PA 1:1 in all the specimen examined, SC 4 except in one specimen with 5. Squama bare. Wing with macrotrichiae rather sparsely, and mainly on the distal half. RR 0.330.50 (0.42), VR 1.09-1.21 (1.14), R/Cu $1.07-1.12(1.10)$. Terminal scale of front tibia (Fig. 25-d) long, narrow and sharply pointed. Terminal combs of middle and hind tibiae (Fig. 25-e) separated, both with a long spur. fLR 2.63-2.89 (2.74), mLR $0.65-0.70$ (0.67), hLR $0.70-0.77$ (0.73), fTR 0.38-0.42 (0.40), fBR 3.9-5.0 (4.5), mBR 4.7-6.6 (5.7), hBR 4.8-6.8 (5.9). Pulvilli absent.

Hypopygium in Fig. 25-g. Bands of ninth tergite separated. Anal point relatively wide, widest at base and apically rounded, with $4-8$ ( 4 in 1,5 in 5,6 in 4,7 in 1,8 in 1 , mean 5.7) spine clusters on a median line. Dorsal appendage (Fig. 25-h, i) roughly oval but with a neck subapically, with 7 or 8 short setae, but without basal seta. Digitus absent. Ventral appendage (Fig. 25-j) finger-like, not swollen apically, with 8 or 9 recurved setae on dorsal side and 3 caudally directed setae on ventral side of apical portion. Median appendage (Fig. 25-j) relatively short and with inwards directed simple setae which do not reach beyond middle of ventral appendage. Gonostylus widest at about basal $1 / 3$, outer margin smoothly convex, inner margin slightly concave.

Remarks. This species belongs to the oyamai group of genus Tanytarsus van der Wulp, 1893, since it is morphologically a typical member of this genus but anal point has lateral ridges and several spine clusters arranged on a longitudinal line, dorsal appendage is roughly oval but has a subapical neck, digitus is absent, and median appendage is short and directed inwards. Four species have been recorded from Japan and Taiwan as members of this group, among which T. oyamai Sasa, 1979, is widely distributed in Japan and its body (including abdominal tergites) is almost uniformly dark brown, while $T$. uraiensis Tokunaga, 1938, was recorded from hotspring in Taiwan and its body is almost uniformly yellow or pale brown, and its dorsal, ventral and median appendages are all more slender than in oyamai so far as its original descriptions concern. On the other hand, T. sakishimanus Sasa et Hasegawa, 1988 recorded from Ishigaki Island, South Okinawa, has a pair of conspicuous yellow areas surrounded by dark brown squares on each of abdominal tergites II to VI. The fourth species which was recorded from Taiwan by Tokunaga (1940) by the name of $T$. formosanus Kieffer is possibly the same as the present species, since it is stated that "abdominal segments one to five yellow, each tergum with a dark, somewhat inverted $\mathrm{T}$-shaped band on caudal margin." However, male hypopygium of this species drawn in the original paper by Kieffer (1912, Fig. 16; also reproduced as Fig. 25-j of this paper) is composed of a narrow, parallel-sided and apically rounded anal point with neither lateral ridges nor spine clusters, and the shape of dorsal appendage is quite different from that of the present species. Since Kieffer's type specimens are said to be all lost, there is no means of con-

Fig. 25 Tanytarsus euformosanus, sp. nov.

a, head; b, frontal tubercles; c, antepronotum; d, tip of front tibia; e, tip of hind tibia; $\mathrm{f}$, abdominal tergites, showing distribution of setae and dark areas; $\mathrm{g}$, hypopygium; $\mathrm{h}$, $\mathrm{i}$, left and right dorsal appendages; $\mathrm{j}$, median and ventral appendages.

Fig. 26 Tanytarsus uraiensis Tokunaga.

a, frontal tubercles; b, tip of front tibia; c, tip of middle tibia; d, tip of hind tibia; $\mathrm{e}$, hypopygium; $f$, dorsal appendage; $g$, median and ventral appendages. 

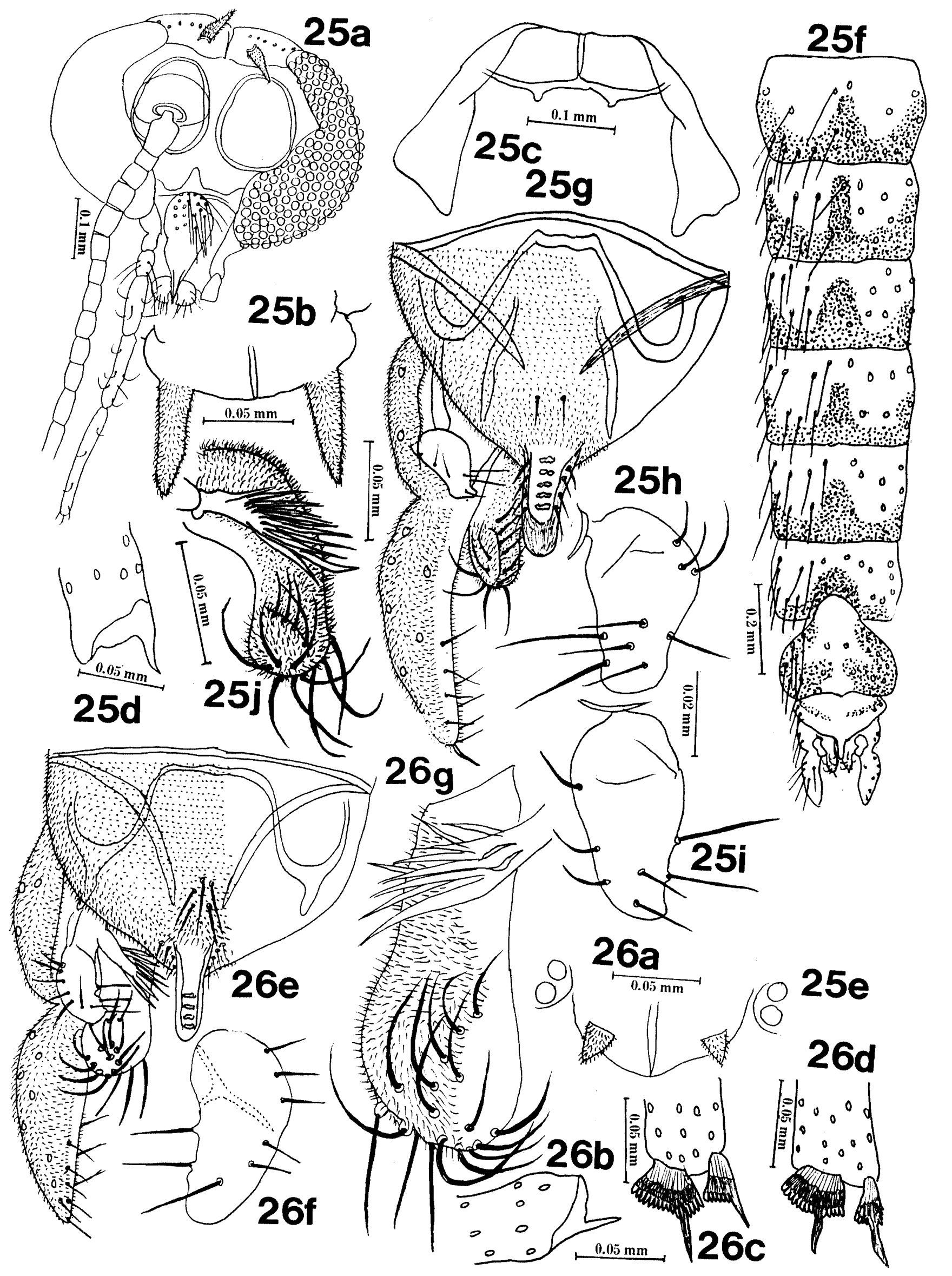

Figs. 25 and 26 
firming whether the present specimens are the same as $T$. formosanus Kieffer, 1912 or not, and the present authors consider that it is safer to create a new species in order to avoid confusion. Hashimoto et al. (1981) described $T$. formosanus Kieffer from Thailand, and also stated that "In Japan, this species is often associating with a related species T. uraiensis Tokunaga." However, the species of this group commonly collected in the mainland of Japan by the present authors, such as T. oyamai Sasa, 1979 and T. konishii Sasa et Kawai, 1985, are quite different from the above two species in body coloration.

\section{Tanytarsus uraiensis Tokunaga, 1938 (Fig. 26)}

Three males were collected at the side of Lake Toba on Jan. 1, 1989 (No. A 200:14, 16, 19). BL 2.86, 2.92, $3.12 \mathrm{~mm}$, WL 1.38, $1.39 \mathrm{~mm}$. Body almost uniformly pale yellow, scutal stripes and postnotum slightly brownish. Eyes bare, ER 0.35, 0.48, 0.48. Frontal tubercles conical (Fig. 26-a), $15 \mu \mathrm{m}$ high, $18 \mu \mathrm{m}$ wide at the base, and $35 \mu \mathrm{m}$ apart from each other. Antenna with 13 flagellar segments, AR 1.04, 1.08, 1.13, AHR 0.50, $0.50,0.54$. SO $8: 10,8: 10,10: 11$, CL 11, 13, 14. Antepronotum without lateral setae. DM 10, 12, 15, DL 8:9, 11:11, 11:12, PA all $1: 1$, SC $4,4,6$. Squama bare. Wing with macrotrichiae more densely and widely than in the preceding species. RR $0.37,0.38$, VR $1.19,1.32, \mathrm{R} / \mathrm{Cu} 1.11,1.14$. Terminal process of front tibia (Fig. 26-b) narrow and sharply pointed. Terminal combs of middle and hind tibiae (Fig. 26-c, d) separated, and both with a long spur. fLR 2.88, mLR 0.59 , $0.68,0.70$, hLR $0.74,0.75,0.77$, fTR 0.43 , fBR 3.5, mBR 3.8, 4.6, 4.7, hBR 4.0, 5.5. Pulvilli absent.

Hypopygium in Fig. 26-e. Bands of ninth tergite separated in the middle. Anal point similar to that of the preceding species, rather stout, parallel-sided and apically rounded, with 4, 4, 6 spine clusters between well developed lateral ridges. Dorsal appendage (Fig. 26-f) roughly oval but inner margin slightly concave, without conspicuous neck such as seen in the preceding species. Ventral and median appendages (Fig. 26-g) similar to that of the preceding species, the latter short and with inwards directed short setae. Gonostylus widest at about basal $1 / 3$, outer margin smoothly convex, inner margin almost straight and with two rows of short setae.

Remarks. The above morphological characters are almost coincident with those of T. uraiensis Tokunaga, 1938, recorded from hotspring water at Urai, Taiwan. It is similar to the preceding species, but differs from it in body coloration (almost entirely pale yellow, without conspicuous dark marks as seen in the preceding species), in the more densely distributed macrotrichiae on wing membrane, and in the shape of dorsal appendage. The present species is also similar in structure to T. oyamai Sasa, 1979, commonly found in Japan, but differs most remarkably in body coloration (entirely dark brown in oyamai).

\section{Paratrichocladius tobanonadeci- mus, sp. nov. (Fig. 27)}

A male was collected at the side of Lake Toba on Jan. 2, 1989 (holotype: No. A 200: 73 ). BL $1.73 \mathrm{~mm}$, WL $0.98 \mathrm{~mm}$. Body largely black or dark brown; ground color of scutum brown, stripes black, scutellum and postnotum also black, abdominal tergites dark brown, femora and tibiae dark brown, tarsi brown, wing unmarked. Head in Fig. 27-a. Eyes pubescent, reniform and without dorsomedial projection, ER 1.33. Antenna with 13 flagellar segments, AR 0.43 (very small), AHR 0.37; last antennal segment very short and apically swollen, with rosette-like sub-

Fig. 27 Paratrichocladius tobanonadecimus, sp. nov.

a, head; b, scutum and scutellum; c, wing; d, tip of front tibia; e, tip of middle tibia;

$\mathrm{f}$, tip of hind tibia; $\mathrm{g}$, distribution of setae on abdominal tergites; $\mathrm{h}$, hypopygium, dorsal view; i, hypopygium, ventral view.

Fig. 28 Eukiefferiella tobavicesima, sp. nov.

$a$, head; $b$, wing; $c$, tip of front tibia; $d$, tip of middle tibia; $e$, tip of hind tibia; $f$, hypopygium, dorsal view; $\mathrm{g}$, hypopygium, ventral view. 


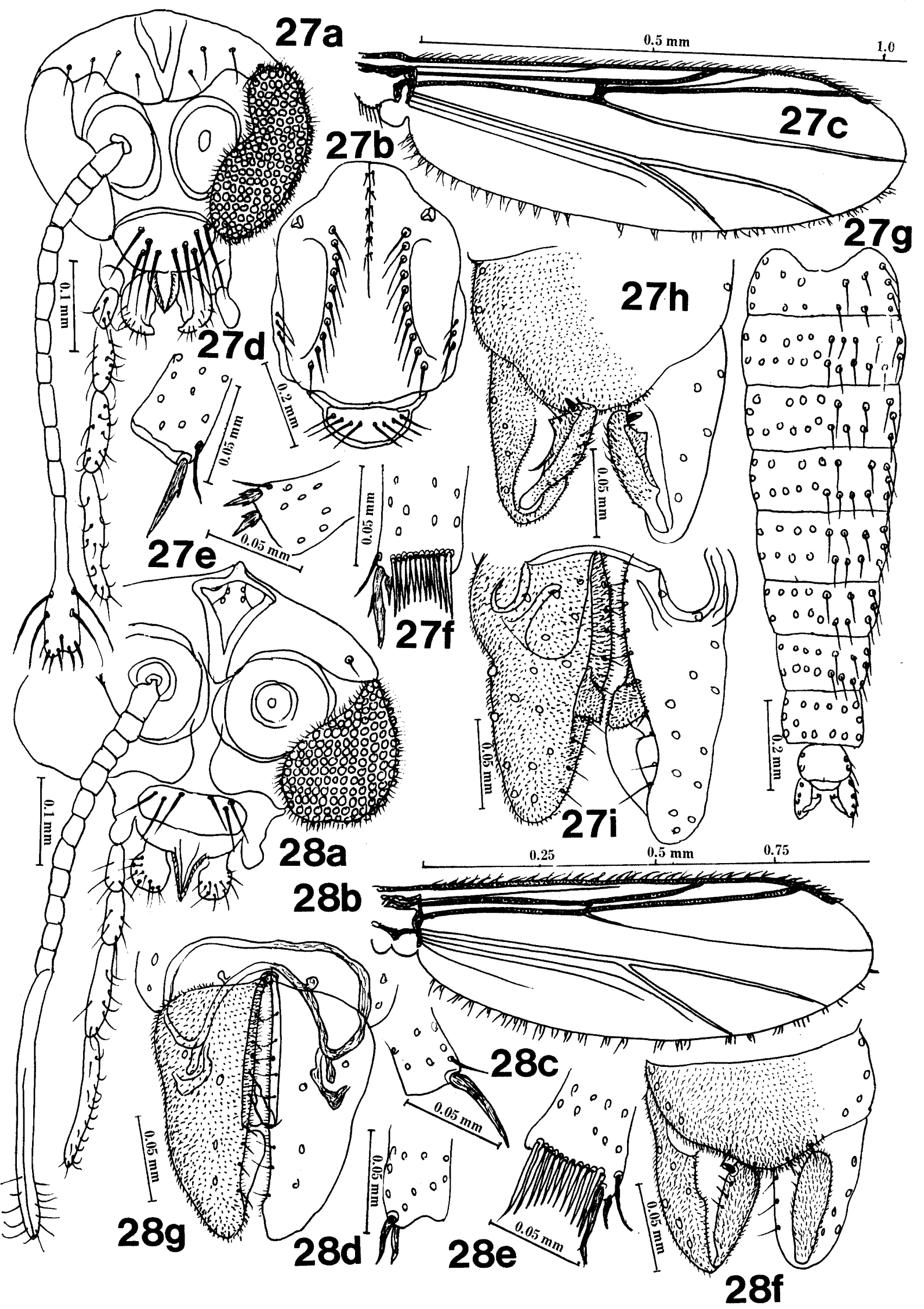

Figs. 27 and 28 
apical sensory setae. SO 4:4, CL 9. Antepronotum with $2: 2$ lateral setae. Scutum and scutellum in Fig. 27-b. DM 12, all minute, DL 10:10, well developed, PA 3:3, SC 8. Wing in Fig. 27-c. Squama with 6:6 fringe hairs. Tip of $\mathrm{R} 4+5$ is just above tip of $\mathrm{Cu} 1, \mathrm{R} / \mathrm{Cu} 1.00$. Costa extending beyond tip of $\mathrm{R} 4+5$. $\mathrm{R} 2+3$ ending about midway between tips of $\mathrm{R} 1$ and $\mathrm{R} 4+5, \mathrm{RR} 0.47$. $\mathrm{Cu} 2$ almost straight. Wing membrane bare, very finely granular, and slightly brownish. Tip of front tibia (Fig. 27-d) with one long terminal spur. Tip of middle tibia (Fig. 27-e) with two short terminal spurs. Tip of hind tibia (Fig. 27-f) with one long spur, one short spur, and a comb composed of 12 free spurs. fLR 0.83, mLR 0.50, hLR 0.60, fTR 0.15 , fBR 2.5, mBR 3.3, hBR 3.5. Pulvilli absent.

Hypopygium in Fig. 27-h, i. Anal point absent. Inner lobe of gonocoxite single, roughly rectangular. Gonostylus simple, and with a strong megaseta, and a triangular subapical tooth.

Remarks. This species is judged as a member of genus Paratrichocladius Santos Abreu, 1918, because eyes are pubescent, wing membrane is bare, squama with fringe setae, $\mathrm{Cu} 2$ is almost straight, dorsolateral setae of scutum are well developed and arising on pale pits, and anal point is absent. The numbers of species recognized as members of this genus by Hirvenoja (1973, p. 90) were two from Palaearctic, two from Nearctic, two from Aethiopian, and one from Australian regions. Three species have been recorded from Japan by Sasa (1989), including two closely related species, rufiventris (Meigen, 1830) and tamaater Sasa, 1981. The present species is structurally most closely related to these species, but they differ from the present species in that $\mathrm{AR}$ is about 1.0 or larger, ninth tergite has long setae in the central portion, inner lobe of gonocoxite is more complicated in shape, and subapical tooth of gonostylus is wider and more rounded. The trivial name is modified from "undevicesimus" (nineteenth).

\section{Eukiefferiella tobavicesima, sp. nov. (Fig. 28)}

A male was collected at the side of Lake
Toba on Jan. 2, 1989 (holotype: No. A 200: 74). BL $160 \mathrm{~mm}$, WL $96 \mathrm{~mm}$. Scutum, scutellum and postnotum dark brown; wing unmarked; abdominal tergites I to III, and oral half of IV pale yellow, the distal parts including hypopygium dark brown; front leg segments brown, excepting trochanter, and distal half of femur paler; in the middle and hind legs, proximal $1 / 3$ of femora dark brown, tarsi $\mathrm{V}$ brown, the rest parts yellow. Head in Fig. 28-a. Eyes pubescent, roughly semiglobular, without dorsomedial projection and widely apart from each other, ER 1.63. Antenna with 13 flagellar segments, AR 0.77, AHR 0.47, last segment not swollen apically. SO $1: 1$, CL 6. Antepronotum without lateral setae. Scutum without dorsomedian setae but with a small pale area (Mesonotalhoecker of Brundin, 1956) in the middle. DL 7:7, PA 2:2, SC 4. Wing in Fig. 28-b. Squama bare. $\mathrm{R} 4+5$ ending much proximal to tip of $\mathrm{Cu} 1$, and costa extending much beyond it. $\mathrm{R} 2+3$ almost fused with $\mathrm{R} 4+5$, RR 0.90 . fCu much beyond $\mathrm{r}-\mathrm{m}$, VR 1.29. Cu2 almost straight. Anal vein extending beyond fCu. Tip of front tibia (Fig. 28-c) with a long terminal spur. Tip of middle tibia (Fig. 28-d) with two short terminal spurs. Tip of hind tibia (Fig. 28-e) with a long spur, a short spur, and a comb composed of 12 free spurs. fLR 0.60 , mLR 0.47 , hLR 0.55 , fTR 0.14, fBR 2.0, mBR 3.0, hBR 4.6. Pulvilli absent.

Hypopygium in Fig. 28-f, g. Anal point absent. Gonocoxite with almost straight inner margin and without inner lobe. Gonostylus simple, almost straight and widest at near apex, with a strong subapical spur.

Remarks. This species is provisionally placed into genus Eukiefferiella Thienemann, 1926, since eyes are pubescent, wing and squama are bare, antenna without apical seta, Cu2 is almost straight, and costa extends beyond tip of R4+5. This genus is heterologous in view of the adult morphology, and the present species belongs to the group with the combination of the following characters; eyes are pubescent, squama bare, $\mathrm{R} 4+5$ ending much proximal to tip of wing and to tip of $\mathrm{Cu} 1, \mathrm{fCu}$ far distal to $\mathrm{r}-\mathrm{m}$, $\mathrm{R} 2+3$ is fused with $\mathrm{R} 4+5$, and anal point is absent. Among the known species of this group, it is most closely related to E. coeru- 
lescens (Kieffer, 1926) recorded from Europe and also from Japan (Sasa and Kawai, 1987a; Sasa, 1988a), but the latter has a large lobe on inner margin of gonocoxite, and antenna is composed of 12 flagellar segments. The trivial name means twentieth in latin.

\section{Pseudosmittia tobaunvicesima, sp. nov. (Fig. 29)}

A male was collected at the side of Lake Toba on Jan. 2, 1989 (holotype: No. A 200: 72). BL $2.04 \mathrm{~mm}$, WL $1.02 \mathrm{~mm}$. Scutum, scutellum and postnotum uniformly dark brown; abdominal tergites II and III entirely yellow, IV to VII each with a dark band along oral margin (Fig. 29-g); coxae of all legs brown, other leg segments brownish yellow. Head in Fig. 29-a. Eyes bare, reniform, ER 1.37. Antenna with only 12 flagellar segments, AR 0.69, AHR 0.45. SO 4:4, CL 6. Antepronotum with $3: 3$ lateral setae. Scutum and scutellum in Fig. 29-b. Scutum without dorsomedian setae but has a small pale area in the middle with two pale dots. DL 6:7, PA $2: 2$, SC 4. Wing in Fig. 29-c. Squama bare. Costa not extending beyond tip of $\mathrm{R} 4+5$, which is located much proximal to tip of $\mathrm{Cu} 1, \mathrm{R} / \mathrm{Cu} 0.93$. $\mathrm{R} 2+3$ separated from both $\mathrm{R} 1$ and $\mathrm{R} 4+5$, tip of $\mathrm{R} 2+3$ slightly beyond the midpoint of the tips of $\mathrm{R} 1$ and $\mathrm{R} 4+5$, RR 0.55. fCu located much distal to $\mathrm{fCu}, \mathrm{VR} 1.50$. Cu2 strongly curved. Anal vein not extending beyond $\mathrm{fCu}$. Tip of front tibia (Fig. 29-d) with a long terminal spur. Tip of middle tibia (Fig. 29-e) with two short terminal spurs. Tip of hind tibia (Fig. 29-f) with a long terminal spur, a short terminal spur, and a comb composed of 12 free spurs. fLR 0.36, mLR 0.41, hLR 0.50 (all extremely low), fTR 0.11 , fBR 2.0 , mBR 2.7, hBR 3.1. Pulvilli absent. Abdominal tergites II to VII with only 6 setae, VIII with 8 setae, as in Fig. 29-g together with the distribution of dark areas.

Hypopygium in Fig. 29-h. Ninth tergite with a broad lobe in the middle of posterior margin, which bears 3 pairs of short setae, but without anal point. Gonocoxite without inner lobe, and with numerous short setae on inner margin. Gonostylus narrow and strongly curved, and with a broad and stout apical spur (megaseta).

Remarks. This species is provisionally classified into genus Pseudosmittia Goetghebuer, 1932 in the sense of Brundin (1956) and Pinder (1978), since wings are bare, squama without fringe hairs, eyes bare, antenna without apical seta, costa not extending beyond tip of $\mathrm{R} 4+5, \mathrm{R} 4+5$ ending much proximal to tip of $\mathrm{Cu} 1(\mathrm{R} / \mathrm{Cu}$ smaller than $1.0), \mathrm{Cu} 2$ is strongly curved, and anal vein not extending beyond fCu. Members of this genus have been classified into the two groups, those with three inner lobes, and those with only one or two inner lobes, but the present species has no inner lobe. It is also quite unusual as a member of this genus in having no anal point, antenna has only 12 flagellar segments, and gonostylus is strongly curved. The trivial name is modified from "vicesimus primus" (twenty first).

\section{Pseudosmittia tobaduovicesima, sp. nov. (Fig. 30)}

A male was collected at the side of Asahan Dam on Jan. 3, 1989 (holotype: No. A 200: 93). BL $1.40 \mathrm{~mm}$, WL $0.77 \mathrm{~mm}$ (both smaller than in the preceding species). Ground color of scutum brown, stripes dark brown, antepronotum, scutellum, postnotum and abdominal tergites also dark brown; proximal $2 / 3$ of femur brown, the rests distal leg segments yellow; halteres yellow, wing unmarked. Head in Fig. 30-a. Eyes bare, oval and without dorsomedian projection, ER 1.61 (unusually high). Antenna with 13 flagellar segments, AR 0.82, AHR 0.53. SO 2:2, CL 4, PN 0:0. Scutum and scutellum in Fig. 30-b. Scutum without dorsomedian setae but with a pale area in the central portion. DL $4: 4$, PA $2: 2$. SC only 2 . Wing in Fig. 30-c. $\mathrm{R} 4+5$ ending far proximal to tip of $\mathrm{Cu} 1$, $\mathrm{R} / \mathrm{Cu} 0.78$ (very small), and costa not extending beyond it. R2+3 is almost fused with $\mathrm{R} 4+5$, RR 0.95. fCu much beyond r-m, VR 1.83 (unusually high). Both Cu1 and $\mathrm{Cu} 2$ ending before reaching wing margin. Anal vein not extending beyond $\mathrm{fCu}$. Squama bare. Tip of front tibia (Fig. 30-d) with a long terminal spur. Tip of middle tibia (Fig. 30-e) with two short terminal spurs. Tip of hind tibia (Fig. 30-f) with a long terminal spur, a short terminal spur, 


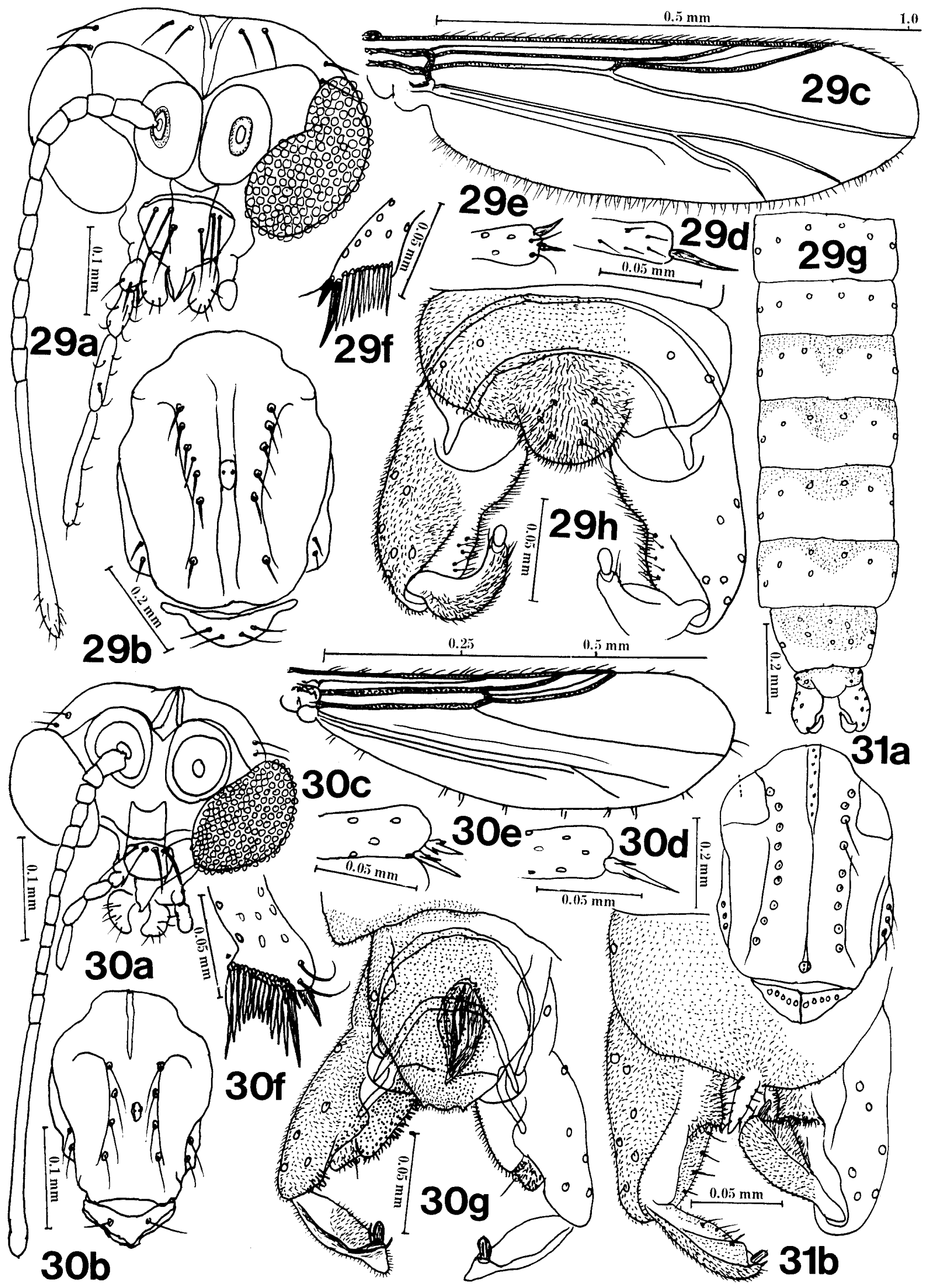

Figs. 29-31 
and a terminal comb composed of 12 free spurs. fLR 0.46, mLR 0.45, hLR 0.47 (all usually small), fTR 0.13 , fBR 3.2, mBR 3.0, hBR 3.3. Pulvilli absent. Abdominal tergites II to VII each with only 6 setae, VIII with 8 setae.

Hypopygium in Fig. 30-g. Ninth tergite with a darky chitinized and structurally complicated anal point in the central portion. Gonocoxite with two very broad and low inner lobes both covered thickly by microtrichiae. Gonostylus simple, almost straight, with a triangular subapical tooth extending beyond middle of inner margin.

Remarks. This species is also considered as to belong to the genus Pseudosmittia Goetghebuer, since wing, squama, eyes are all bare, scutum without dorsomedian setae and with a central pale pit, $\mathrm{R} 4+5$ is ending much proximal to tip of $\mathrm{Cu} 1$ and costa does not extend beyond it, and $\mathrm{fCu}$ is much beyond $\mathrm{r}-\mathrm{m}$. It differs from the preceding species in body coloration being almost entirely dark brown, eyes are bare, $\mathrm{R} 2+3$ is fused with $\mathrm{R} 4+5$, and in various measurement data. The presence of anal point with highly complicated structure is also characteristic to this species. The trivial name is modified from "vicesimus alter" (twenty second).

\section{Rheocricotopus tobatervicesimus, sp. nov. (Fig. 31)}

A male was collected at the side of Lake Toba on Jan. 1, 1989 (holotype: No. A 200: 22). BL $2.02 \mathrm{~mm}$, WL $1.06 \mathrm{~mm}$. Body largely dark brown or black. Scutum with a pair of large pale areas in the humeral portion (HM in Fig. 31-a), otherwise black; scutellum and postnotum black; abdominal tergites dark brown, sternites brown; femora and tibiae dark brown, tarsi brown; wing un- marked.

Eyes highly pubescent, reniform and inner margin concave but without dorsomedial projection, ER 1.30. Antenna with 13 flagellar segments, AR 0.45, AHR 0.41, last segment swollen apically and with many sensory setac. SO 6:6. CL 9. Antepronotum with $3: 3$ lateral setae. Scutum and scutellum in Fig. 31-a. DM 8, all minute. DL 9:9, well developed and each arising on a large pale pit. PA $3: 3$, SC 10. Squama with $4: 3$ fringe hairs. Costa extending slightly beyond tip of $\mathrm{R} 4+5$, which is slightly distal to tip of $\mathrm{Cu} 1, \mathrm{R} / \mathrm{Cu} 1.02$. $\mathrm{R} 2+3$ ending about midway between tips of $\mathrm{R} 1$ and $\mathrm{R} 4+5$, RR 0.48 . $\mathrm{fCu}$ beyond $\mathrm{r}-\mathrm{m}, \mathrm{VR}$ 1.18. Cu2 nearly straight. Anal vein ending under fCu. Terminal structure of tibiae as in other Orthocladiini, namely, front tibia with one long terminal spur, middle tibia with two short terminal spurs, hind tibia with one long and one short terminal spurs, and a terminal comb composed of 12 free spurs. fLR 0.64 , mLT 0.49 , hLR 0.56, fTR 0.16, fBR 3.0, mBR 3.2, hBR 3.4. Pulvilli absent.

Hypopygium in Fig. 31-b. Anal point narrow, pointed apically and with lateral setae. Inner lobe of gonocoxite roughly rectangular but with rounded margin. Gonostylus simple, with a strong megaseta, and a rectangular subapical tooth.

Remarks. This specimen is considered as to belong to the genus Rheocricotopus Thienemann et Harnisch, 1932, since wings are bare, squama fringed, eyes are pubescent, scutum with a pair of large humeral pits, and anal point is robust and with lateral setae. Among the known species of this genus, it is most closely related to $R$. foveatus (Edwards, 1929) known from Europe in that humeral pits are large and subapical tooth of gonostylus is roughly rectangular, but is quite different in AR (1.0-1.1 in foveatus), anal

Fig. 29 Pseudosmittia tobaunvicesima, sp. nov.

$a$, head; b, scutum and scutellum; $c$, wing; $d$, tip of front tibia; $e$, tip of middle tibia; $f$, tip of hind tibia; $\mathrm{g}$, abdominal tergites II to hypopygium, showing distribution of setae and of dark areas; h, hypopygium.

Fig. 30 Pseudosmittia tobaduovicesima, sp. nov.

a, head; b, scutum and scutellum; c, wing; $d$, tip of front tibia; e, tip of middle tibia; $f$, tip of hind tibia; $\mathrm{g}$, hypopygium, dorsal view.

Fig. 31 Rheocricotopus tobatervicesimus, sp. nov.

a, scutum and scutellum; b, hypopygium, dorsal view. 
point is apically rounded (sharply pointed in foveatus). It is also somewhat related to $R$. tamahumeralis Sasa, 1981 recorded from River Tama, Japan, in that gonostylus is nearly straight and large humeral pits are present, but also differs in AR (1.10-1.28 in tamahumeralis), in the numbers of scutal setae (DM 22-32, DL 11-14), in the structure of inner lobe of gonocoxite (with an accessory process), and in the presence of subapical tooth of gonostylus (this is absent in tamahumeralis). The trivial name is modified from "vicesimus tertius" (twenty third).

\section{Acknowledgements}

The authors are greatly indebted to Dr. T. Suzuki and his colleagues of the JICA Mission for Medical Cooperation to Asahan Project, and its Indonesian counterparts for their generous assistance to this study.

\section{REFERENCES}

Brundin, L. (1956): Zur Kenntnis der Orthocladiinae (Chironomidae). Rep. Ins. Freshwater Res. Drottingholm, 37: 1-175.

Edwards, F. W. (1928): Insects Samoa, 6(2): 67.

Edwards, F. W. (1929): British non-biting midges. Trans. R. Entomol. Soc. Lond., 77: 279-429.

Freeman, P. (1961): The Chironomidae of Australia. Austr. J. Zool., 9: 611-737.

Goetghebuer, M. (1937): Tendipedidae. In: Die Fliegen der palaearktischen Region (ed., Lindner, E.), Vol. 13c, 138pp., E. Schweizerbart'sche Verlagsbuchhandlung, Stuttgart.

Hashimoto, H. (1984): Notes on Chironomus javanus Kieffer from Japan. Proc. Jpn. Soc. Syst. Zool., 29: 24-29.

Hashimoto, H., T. Wongsiri, N. Wongsiri, C. Tirawat, A. Lewvanich and $\mathrm{K}$. Yasumatsu (1981): Chironominae from rice fields of Thailand with description of 7 new species. In: Tech. Bull. No. 007, pp. 1-47, Entomology and Zoology Div. Dept. Agric., Bangkok, Thailand.

Hirvenoja, M. (1973): Revision der Gattung Cricotopus van der Wulp und ihrer Vervandten (Diptera, Chironomidae). Ann. Zool. Fenn., 10: $1-363$.

Johannsen, O. A. (1932): Tanypodinae from the Malayan Subregion of the Dutch East Indies. Arch. Hydrobiol. (Suppl.), 9: 493-507.

Johannsen, O. A. (1932): Orthocladiinae of the
Malayan subregion of the Dutch East Indies. Arch. Hydrobiol. (Suppl.), 9: 715-732.

Johannsen, O. A. (1932): Chironominae of the Malayan subregion of the Dutch East Indies. Arch. Hydrobiol. (Suppl.), 11: Tropische Binnengewass. Bd. III, 503-552.

Kieffer, J. J. (1912): Tendipediae (Dipt.). Formosa-Ausbeute, H. Sauter. Suppl. Entomol., 1: $27-43$.

Kieffer, J. J. (1916): Tendipedides (Chironomidae) de Formose. Ann. Musei Nat. Hungarici, 14: $81-121$.

Kieffer, J. J. (1921) : Chironomides des Philippines et de Formose. Philipp. J. Sci., 18: $557-$ 593.

Kieffer, J. J. (1922): Etudes sur les Chironomidae de Formose. Ann. Soc. Linn. Lyon, 69: 27-41.

Kieffer, J. J. (1924) : Chironomides non piqueurs de Java. Ann. Soc. Sci. Brux., 43: 262-270.

Lehmann, J. (1970) : Revision der europaeischen Arten der Gattung Parachironomus Lenz. Hydrobiologia, 33: 129-158.

Lenz, F. (1937): Chironomariae aus Niederlaendisch-Indien. Larven und Puppen. Arch. Hydrobiol. (Suppl.), 15: 1-29.

Pinder, L. C. V. (1978): Freshwater Biol. Assoc. Sci. Publ. No. 37, A Key to Adult Males of British Chironomidae, 169 pp., Figs. 189, The Ferry House, Ambleside, Cumbria LA 22 oLP.

Saether, O. A. (1977): Taxonomic studies on Chironomidae: Nanocladius, Pseudochironomus, and the Harnischia complex. Bull. Fish Res. Board, Canada, 196: 1-287.

Sasa, M. (1978): A comparative study of adults and immature stages of nine Japanese species of the genus Chironomus (Diptera, Chironomidae). Res. Pep. NIES, No. 3, 1-63.

Sasa, M. (1979a): Taxonomic accounts on the so-called Chironomus dorsalis complex of Japan. Jpn. J. Sanit. Zool., 30: 187-192.

Sasa, M. (1979b): A morphological study of adults and immature stages of 20 Japanese species of the family Chironomidae (Diptera). Res. Rep. NIES, No. 7: 1-148.

Sasa, M. (1981a): Studies on chironomid midges of the Tama River. Pt. 3. Species of the subfamily Orthocladiinae recorded at the summer survey and their distribution in relation to the pollution with sewage waters. Res. Rep. NIES, No. 29: 1-78.

Sasa, M. (1981b): Studies on chironomid midges of the Tama River. Pt. 4. Chironomidae recorded at a winter survey. Res. Rep. NIES, No. 29: 79-148.

Sasa, M. (1985a): A report on the chironomids collected in winter from the Sapporo area, Hokkaido (Diptera, Chironomidae). Res. Rep. 
NIES, No. 83: 1-23.

Sasa, M. (1985b): Studies on the chironomids collected from lakes in southern Kyushu (Diptera, Chironomidae). Res. Rep. NIES, No. 83: 25-99.

Sasa, M. (1985c): Studies on the chironomids collected from lakes in the Mount Fuji Area (Diptera, Ghironomidae). Res. Rep. NIES, No. 83: $101-160$.

Sasa, M. (1988a): Studies on the chironomid midges collected from lakes and streams in the southern region of Hokkaido, Japan. Res. Rep. NIES, No. 121: 8-76.

Sasa, M. (1988b) : Chironomid midges collected on the shore of lakes in the coastal region of Abasiri, northern Hokkaido. Res. Rep. NIES, No. 121: 77-90.

Sasa, M. (1988c): Chironomid midges collected on the shore of a highly eutrophicated Lake Kojima (Okayama). Seikatsu to Kankyo, 33: 54-57 (in Japanese).

Sasa, M. (1989a): Chironomidae of Japan: checklist of species recorded, key to males and taxonomic notes. Res. Rep. NIES, No. R-12589, 1-177.

Sasa, M. (1989b): Studies on the chironomid midges (Diptera, Chironomidae) of Shou River. Res. Rep. Toyama Prefect. Environ. Pollut. Res. Cent., 1989: 26-44, 87-95.

Sasa, M. (1989c): Chironomid midges of some rivers in western Japan. Res. Rep. Toyama Prefect. Environ. Pollut. Res. Cent., 1989: 4586, 97-110.

Sasa, M. and H. Hasegawa (1983): Chironomid midges of the tribe Chironomini recovered from sewage ditches, eutrophicated ponds and clean streams of the Ryukyu Islands, southern Japan. Jpn. J. Sanit. Zool., 34: 305-341.

Sasa, M. and H. Hasegawa (1988): Additional records of the chironomid midges from the Ryukyu Islands, southern Japan. Jpn. J. Sanit. Zool., 39: 229-256.

Sasa, M. and K. Kawai (1985): Morphological accounts on selected chironomids collected in Toyama. Bull. Toyama Sci. Museum, 7: 7-22.

Sasa, M. and K. Kawai (1987a): Studies on the chironomid midges of Lake Biwa (Diptera, Chironomidae). In: Lake Biwa Study Monograph 3, 119 pp., Lake Biwa Research Institute, Ohtsu, Japan.

Sasa, M. and K. Kawai (1987b): Studies on the chironomid midges of the Stream Itachigawa, Toyama. Bull. Toyama Sci. Museum, 10: 25-
72.

Sasa, M., K. Kawai and R. Ueno (1988): Studies on the chironomid midges of Oyabe River, Toyama. Res. Rep. Toyama Prefect. Environ. Pollut. Res. Cent., 1988: 26-85.

Tokunaga, M. (1936): Chironomidae from Japan. VII. New species and a new variety of the genus Chironomus Meigen. Philipp. J. Sci., 60: 71-85.

Tokunaga, M. (1938): Chironomidae from Japan. X. New or little known midges with descriptions of the metamorphoses of several species. Philipp. J. Sci., 65: 318-383.

Tokunaga, M. (1939): Chironomidae from Japan. XI. New or little known midges with special references to the metamorphoses of torrential species. Philipp. J. Sci., 69: 297-345.

Tokunaga, M. (1940): Chironomidae from Japan. XII. New or little known Ceratopogonidae and Chironomidae. Philipp. J. Sci., 72: 255317.

Tokunaga, M. (1964): Diptera, Chironomidae. In: Insects of Micronesia, Vol. 12, No. 5, pp. 485-628, Bishop Museum, Honolulu.

Townes, H. K., Jr. (1945): The Nearctic species of Tendipedini. Am. Midl. Nat., 34: 1-206.

Yamamoto, M. (1981): Two new species of the genus Stenochironomus from Japan. Bull. Kitakyushu Mus. Nat. Hist., 3: 41-51.

Zavrel, J. (1934): Tanytarsuslarven und -puppen aus Niederlaendisch-Indien. Arch. Hydrobiol. (Suppl.), 13: 139-165.

\section{摘要 \\ インドネシア国スマトラ島のトバ湖岸で 採集したユスリカ類}

スマトラのトバ湖岸で1987年 1 月より1989年 1 月の 間に 3 回, ユスリカの成虫の採集を行った，それには： 捕虫網，ないし吸虫管による昼間の捕集と，夜間に池 で作動する䖝光灯に誘引される成虫の吸虫管による捕 集とを併用した，それの標本はスライドガラスにガム クロラール液で封入標本とし, 主として雄成虫で種の 鑑別を行った結果, 101 匹の雄が31種に分類され, そ のうち 26 種は Chironominae 亜科, 5 種は Orthocladiinae 亜科に属するものであった。 これらのうち， 20 種は新種, そのうち 3 種は新属の新種として新たに 学名を与えた.インドネシアを含む東南アジアに産す るユスリカ科についてはこれまできわめて記録が少な かったが，今回の調查でも多くの未記録のユスリカが 分布することが示され，それらには分類学的にもきわ めて斬新な種類が含まれていた. 